\title{
Coral and macroalgal exudates vary in neutral sugar composition and differentially enrich reef bacterioplankton lineages
}

\author{
Craig E Nelson ${ }^{1}$, Stuart J Goldberg ${ }^{1}$, Linda Wegley Kelly ${ }^{2}$, Andreas F Haas ${ }^{3}$, \\ Jennifer E Smith ${ }^{3}$, Forest Rohwer ${ }^{2}$ and Craig A Carlson ${ }^{1,4}$ \\ ${ }^{1}$ Marine Science Institute, University of California, Santa Barbara, CA, USA; ${ }^{2}$ Department of Biology, \\ San Diego State University, San Diego, CA, USA; ${ }^{3}$ Scripps Institution of Oceanography, University of \\ California, San Diego, CA, USA and ${ }^{4}$ Department of Ecology, Evolution and Marine Biology, University \\ of California, Santa Barbara, CA, USA
}

\begin{abstract}
Increasing algal cover on tropical reefs worldwide may be maintained through feedbacks whereby algae outcompete coral by altering microbial activity. We hypothesized that algae and coral release compositionally distinct exudates that differentially alter bacterioplankton growth and community structure. We collected exudates from the dominant hermatypic coral holobiont Porites spp. and three dominant macroalgae (one each Ochrophyta, Rhodophyta and Chlorophyta) from reefs of Mo'orea, French Polynesia. We characterized exudates by measuring dissolved organic carbon (DOC) and fractional dissolved combined neutral sugars (DCNSs) and subsequently tracked bacterioplankton responses to each exudate over $48 \mathrm{~h}$, assessing cellular growth, DOC/DCNS utilization and changes in taxonomic composition (via 16S rRNA amplicon pyrosequencing). Fleshy macroalgal exudates were enriched in the DCNS components fucose (Ochrophyta) and galactose (Rhodophyta); coral and calcareous algal exudates were enriched in total DCNS but in the same component proportions as ambient seawater. Rates of bacterioplankton growth and DOC utilization were significantly higher in algal exudate treatments than in coral exudate and control incubations with each community selectively removing different DCNS components. Coral exudates engendered the smallest shift in overall bacterioplankton community structure, maintained high diversity and enriched taxa from Alphaproteobacteria lineages containing cultured representatives with relatively few virulence factors (VFs) (Hyphomonadaceae and Erythrobacteraceae). In contrast, macroalgal exudates selected for less diverse communities heavily enriched in copiotrophic Gammaproteobacteria lineages containing cultured pathogens with increased VFs (Vibrionaceae and Pseudoalteromonadaceae). Our results demonstrate that algal exudates are enriched in DCNS components, foster rapid growth of bacterioplankton and select for bacterial populations with more potential VFs than coral exudates.
\end{abstract}

The ISME Journal (2013) 7, 962-979; doi:10.1038/ismej.2012.161; published online 10 January 2013

Subject Category: microbe-microbe and microbe-host interactions

Keywords: coral; algae; reef; bacteria; exudate; DCNS

\section{Introduction}

Macroalgae and coral holobionts (that is, the coral cnidarian and symbiotic algae and bacteria) are the dominant benthic primary producers in tropical reef ecosystems worldwide. Over the past several decades, there have been reports of ongoing shifts in the relative abundance of these two groups on multiple reefs, with observations of increased algal cover

Correspondence: CE Nelson, Center for Microbial Oceanography, Research and Education, Department of Oceanography, School of Ocean and Earth Science and Technology, University of Hawai'i at Mānoa, Honolulu, HI 96288, USA.

E-Mail: craig.nelson@hawaii.edu

Received 3 July 2012; revised 15 October 2012; accepted 26 October 2012; ; published online 10 January 2013 often associated with a decline in the 'health' of the ecosystem (Hughes, 1994; McCook, 1999; Pandolfi et al., 2003; Ledlie et al., 2007). It has been proposed that climate- or pollution-induced increases in coral disease or bleaching (Diaz-Pulido and McCook, 2002) coupled with eutrophication and/or overfishing of herbivores (McCook et al., 2001; Smith et al., 2010) have either caused direct coral mortality or have enhanced algal competitiveness and subsequently increased algal dominance (Nyström, 2006).

Even after local disturbances are mitigated, these shifts to algal-dominated states may be maintained through a positive feedback, whereby algae remain dominant and suppress coral recovery through a combination of effects on nutrient availability, microbial activity and/or allelopathy (Hughes 
et al., 2007; Ledlie et al., 2007; Birrell et al., 2008; Vermeij et al., 2009; Rasher and Hay, 2010). Differences in the amount and composition of labile dissolved organic carbon (DOC) exuded by corals and algae as a portion of their daily production may support this feedback by influencing the growth rate and community composition of bacterioplankton in the surrounding water (Smith et al., 2006; Haas et al., 2011; Kelly et al., 2012). These DOC exudates may have a central role in coral-algal interactions and reef biogeochemical processes, but little is known of the composition of these exudates or the bacterial communities for which they may select.

Recent advances in culture-independent microbiology have demonstrated that the coral holobiont and the surrounding plankton harbor diverse and distinct microbial communities (Wegley et al., 2007; Barott et al., 2011; Nelson et al., 2011). The role of these communities in reef ecosystems has come under scrutiny with the widespread interest in coral diseases, many of which are demonstrably associated with microbial pathogens (Rosenberg et al., 2007; Dinsdale and Rohwer, 2011). However, these microbial communities also have a key role in reef ecosystem function, serving as the dominant recyclers of organic matter and an important conduit in reef food webs (Grigg et al., 1984; Ducklow, 1990; Sorokin, 1990; Arias-Gonzalez et al., 1997). One of the primary resources for heterotrophic marine microorganisms is dissolved organic matter (DOM), a heterogenous pool of compounds that varies widely in composition and lability (Hansell and Carlson, 2002). The bulk of the accumulated DOM in surface waters of the tropical oceans is resistant to rapid microbial degradation on the timescales of weeks to months (Carlson, 2002), but in shallow nearshore habitats, various benthic organisms have been shown to release significant quantities of DOM, of which a portion is more bioavailable than the bulk background DOM pool (Ducklow, 1990; Haas et al., 2011). Alteration of the metabolism or composition of microbial communities through release of bioavailable DOM has been hypothesized as an indirect mechanism by which algae may facilitate coral decline, possibly through microbialinduced hypoxic stress (Smith et al., 2006) or through selection of opportunistically pathogenic microorganisms (Dinsdale and Rohwer, 2011).

Rates of DOM utilization and efficiency of biomass conversion are regulated by the interactions between community structure, DOM biochemical composition and the ambient nutrient field. Specific groups of heterotrophic bacteria have been shown to exhibit differential utilization of organic substrates of varying quality and quantity (Cottrell and Kirchman, 2000; Carlson et al., 2004; Elifantz et al., 2005; Nelson and Carlson, 2012). Previous studies have shown that bacterioplankton and DOC are depleted in the waters overlying coral reefs relative to offshore waters and that the reef bacterioplankton communities are distinct from those of the open ocean (McCliment et al., 2011; Nelson et al., 2011). These results indicate that reef DOM supports a unique community able to metabolize both reef-derived and oceanic DOM, but experimental tests of these processes are required to clarify these relationships. Seawater culture techniques, in which a naturally occurring population of bacteria is inoculated in particle-free seawater media, allows for the simultaneous monitoring of bacterioplankton growth and DOM utilization and is one approach used to assess the availability of DOM to natural assemblages of bacterioplankton (Ammerman et al., 1984; Carlson and Ducklow, 1996; Haas et al., 2011). By analyzing shifts in community structure among dilution cultures amended with DOM of varying composition, changes in community structure can be coupled with cell growth and DOM utilization to infer linkages between structure and function (Carlson et al., 2004; Nelson and Carlson, 2011, 2012). Furthermore, by characterizing biochemical changes in the DOM among incubations, we can begin linking bacterioplankton populations with selected components of the complex DOM pool.

DOM comprises a complex mixture of major chemical compound classes, such as carbohydrates, proteins and lipids (Wetzel and Likens, 2000; Hansell and Carlson, 2002), with carbohydrates representing the largest identified fraction of oceanic DOM (Benner, 2002). These compound classes are enriched within recently produced DOM, and their concentrations and proportion of total DOC decrease with ongoing diagenetic alteration (Benner, 2002; Goldberg et al., 2011). Qualitative shifts in the overall chemical complexity of the bulk DOM pool may thus be inferred by investigating the variation in the composition and concentration of the carbohydrate pool (Cowie and Hedges, 1994; Goldberg et al., 2011). Throughout the open ocean, acidhydrolysable carbohydrates account for $\leqslant 30 \%$ of surface DOC concentrations (Pakulski and Benner, 1994); fractional dissolved combined neutral sugar (DCNS) can account for up to $30 \%$ of this carbohydrate pool (Benner, 2002) and can be an important substrate used to meet the metabolic needs of heterotrophic bacterioplankton (Rich et al., 1996; Amon et al., 2001; Kirchman et al., 2001). Examining the variability in DCNS composition provides insight to DOM availability and diagenetic state (Skoog and Benner, 1997; Kirchman et al., 2001; Goldberg et al., 2009; Kaiser and Benner, 2009). The proportional contribution of DCNS concentrations to those of total DOC (known as DCNS yield) is often used as a proxy to track the diagenetic state or the relative 'freshness' of ambient DOM (Skoog and Benner, 1997; Amon et al., 2001), with higher yields indicating a DOM pool that is fresher and less degraded. The variation in the molar percentages of specific neutral sugars relative to DCNS concentrations (known as mole \% DCNS) can also be used to track diagenetic patterns in oceanic DOM (Skoog and Benner, 1997; Goldberg et al., 2009, 2011; Kaiser and Benner, 2009). 
Here we present the results of an experiment explicitly designed to test the community- and population-level responses of bacterioplankton to DOM of varying chemical composition released from four common benthic primary producers in the reefs of Mo'orea, French Polynesia. We collected specimens of three macroalgae (Ochrophyta, Rhodophyta and Chlorophyta) and a hermatypic coral (massive Porites spp.) and harvested exudates released after a single daylight cycle $(\sim 8 \mathrm{~h})$, measuring both the rates of exudate DOC production and the DCNS composition of the exudates. We subsequently used these exudates as amendments to dark seawater growth experiments where intact ambient reef bacterioplankton communities are diluted and grown on the enriched seawater media. We tracked changes in bacterial abundance, concentrations of DOC, DCNS quantity and composition and bacterial community structure (via 16S rRNA amplicon pyrosequencing) over $48 \mathrm{~h}$. Our experiments characterize and differentiate the DOM exuded from corals and algae and assess how variation in DOM character translates into bacterioplankton population and community responses, including community growth rates, DOC and DCNS lability and differential selection of bacterial taxa.

\section{Materials and methods}

\section{Study site and specimen collection}

The experiments detailed here were conducted from 5 to 19 September 2010 at the Richard B. Gump South Pacific Research Station located on the north shore of the island of Mo'orea, Society Islands, French Polynesia (17.48S 149.84 W). The island and its reefs are the site of multiple long-term ecological research programs, including the Mo'orea Coral Reef Long Term Ecological Research program under which this research was conducted (http://mcr. lternet.edu). The four different species of primary producers investigated in this study (Supplementary Figure S1) are among the most abundant benthic macroorganisms found in backreef habitats of Mo'orea (http://mcr.lternet.edu/data), comprising three dominant macroalgal genera (each representing a different algal phylum: Turbinaria ornataOchrophyta; Amansia rhodantha-Rhodophyta; Halimeda opuntia-Chlorophyta) and two species of hermatypic coral holobiont (Porites lobata and Porites lutea-commonly collectively considered massive Porites spp. due to difficulty of visual distinction, but see Forsman, et al., 2009).

Specimens were collected from water depths of 0.5-1.5 $\mathrm{m}$ in the backreef waters of the north shore of Mo'orea in replicates of at least 20 using SCUBA as whole individuals (algae) or as unattached whole colonies (coral). Surface areas of individuals were as follows (mean \pm one s.d.): T. ornata $4.9 \pm 0.2 \mathrm{dm}^{2} ; A$. rhodantha $5.1 \pm 0.2 \mathrm{dm}^{2} ; H$. opuntia $5.3 \pm 0.1 \mathrm{dm}^{2}$; and Porites spp. $1.4 \pm 0.1 \mathrm{dm}^{2}$. Mean surface areas of macroalgal specimens did not differ significantly but all were significantly greater than coral specimens (analysis of variance (ANOVA) $P<0.001$ with Tukey's post hoc test $\alpha=0.05)$. Specimens were collected in polyethylene bags (Ziplock) that were stored in seawater-filled coolers to avoid temperature stress and transferred without air exposure to cultivation tanks within $1 \mathrm{~h}$ of sampling. Glass aquaria (40-100l) were provided with fresh seawater flow-through, and temperature and light conditions were monitored and cross-checked with in situ conditions using HOBO Pendant UA-002-64 (Onset Computer Corporation, Bourne, MA, USA) light and temperature loggers. To avoid contamination of the exudates through leakage of intracellular organic matter due to potential injuries from the sampling procedure, all specimens were sampled at least $48 \mathrm{~h}$ before the respective incubation experiment and left to heal in the cultivation tanks. Special care was taken to exclude specimens infested with epibionts or endolithic boring organisms to avoid potential contamination of the targeted exudates. Further details on sample collection can be found in a companion paper (Haas et al., 2011).

DOM exudation and dilution culture incubations Replicate specimens from separate coral or algal colonies $(n=5)$ were incubated in polypropylene beakers (sulfuric acid-cleaned and seawater-leached) filled with exactly $800 \mathrm{ml}$ of filter-sterilized ambient seawater $(0.2 \mu \mathrm{m}$ polyethersulfone filter pre-flushed with $1 \mathrm{l}$ deionized water, SUPOR-200, Pall Corporation, Port Washington, NY, USA) collected from the same location. Beakers were covered with polyethylene film and incubated for a single daylight cycle (0900-1700 hours) in a recirculating ambient seawater bath, with shaded natural light to simulate the temperature and light conditions in the natural backreef habitat $(0.5-1.5 \mathrm{~m}$ water depth, midday photosynthetically active radiation $\sim 600$ $\mu \mathrm{mol}$ quanta $\left.\mathrm{m}^{-2} \mathrm{~s}^{-1}\right)$. Replicate seawater controls $(n=3)$ were incubated in parallel. Additional details on exudation, including net primary production and DOC release, are reported in a companion paper (Haas et al., 2011).

Following exudation, specimens were removed from the beakers using acid-washed forceps, and the remaining incubation water was pooled and gently gravity filtered through a pre-flushed (11 loworganic deionized water; Nanopur Diamond, Barnstead Thermo Scientific, Asheville, NC, USA) $0.2-\mu \mathrm{m}$ polyethersulfone filter (Pall SUPOR-200). This 0.2$\mu \mathrm{m}$ filtrate was used as growth media for replicate $3 \mathrm{l}$ dark seawater cultures conducted in acid-cleaned and media-rinsed polyethylene carboys (23020010, Nalgene Thermo Scientific, Rochester, NY, USA). The filtered media was inoculated with unfiltered backreef seawater (2:5 volumetric ratio) to add a compositionally representative ambient microbial 
community to the sample (Ammerman et al., 1984; Hagström et al., 1984; Carlson and Ducklow, 1996). For each exudate, type two replicate incubations were run in parallel with one control incubation (using as media sterile-filtered seawater incubated alongside specimens and inoculated with the same ambient microbial community) for a total of four replicate control incubations run independently over the course of the four exudate incubation periods comprising the complete experiment. For each exudate treatment, a parallel incubation was run in $2 \mathrm{l}$ acid-cleaned and media-rinsed polycarbonate bottles to test for plastic and handling effects; these incubations were kept closed throughout the experiment and used only for community analysis at $48 \mathrm{~h}$ (see below). DOM and DCNS released from interstitial fluid of algal and coral tissue cannot be differentiated from other forms of exudation, and thus are included in our estimates of DOM production.

\section{Sample collection and processing}

Samples for DOC and bacterial cell abundance were drawn from sample-rinsed platinum-cured silicone tubes at the base of each incubation bottle. Incubation bottles were then kept at in situ temperature in the dark over a time period of $\sim 48 \mathrm{~h}(45-50 \mathrm{~h})$ before sampling DOC again at the final time point. DOC samples $(40 \mathrm{ml})$ were collected in acid-washed and sample-rinsed polyethylene bottles and stored at $-20^{\circ} \mathrm{C}$ for up to 4 months until analysis via hightemperature catalytic oxidation (Carlson et al., 2010). The concentrations and compositions of DCNS were determined from these same samples according to Goldberg et al. (2009, 2010); detailed methods of DCNS analysis are reported in the Supplementary Materials. Samples for bacterioplankton cell abundances (1-2 ml) were collected roughly every $8 \mathrm{~h}$, immediately fixed to $0.5 \%$ paraformaldehyde, flash frozen $\left(-80^{\circ} \mathrm{C}\right)$ and stored for 2 months before enumeration via flow cytometry according to Nelson et al. (2011).

Bacterioplankton DNA, used to assess community shifts in response to the DOM exudates, was collected at $\sim 48 \mathrm{~h}$ by gravity filtering $\sim 2 \mathrm{l}$ through a $10-\mu \mathrm{m}$ polycarbonate prefilter onto a $0.2-\mu \mathrm{m}$ polyethersulfone filter (Sterivex, EMD Millipore, Billerica, MA, USA). The Sterivex cartridge was filled with sucrose lysis buffer $\left(750 \mathrm{mmoll}^{-1}\right.$ sucrose, $400 \mathrm{mmol} \mathrm{l}^{-1} \mathrm{NaCl}, 50 \mathrm{mmol} \mathrm{l}^{-1}$ Tris-HCl and $20 \mathrm{mmoll}^{-1}$ ethylene diamine tetraacetic acid) and flash frozen $\left(-80^{\circ} \mathrm{C}\right)$ until further processing (within 6 months of collection) as described previously (Nelson et al., 2011). DNA was also collected identically directly from the inoculum and the ambient water used during the exudation to define starting of ambient seawater communities. Genomic DNA was extracted, and 16S ribosomal RNA gene fragments were amplified and pyrosequenced (Laboratory of Stephan Schuster at Pennsylvania
State University), with bacterial community phylogenetics and bioinformatics conducted as previously described (Nelson and Carlson, 2012); multiplexing barcodes and updates to the bioinformatic workflow are detailed in Supplementary Materials. Pyrosequencing runs are deposited in the NCBI Sequence Read Archive (http://trace. ncbi.nlm.nih.gov/Traces/sra) as accession SRA054578.

\section{Estimation of putative virulence factors ( VFs) in genomes of enriched bacterioplankton}

$16 \mathrm{~S}$ amplicon sequences of operational taxonomic units (OTUs) significantly enriched in specific treatments were aligned to complete microbial genomes to identify the nearest cultured isolates with sequenced genomes (NCBI genomic BLAST, $E$-value $<\mathrm{e}^{-5}$ ). Representative genomes were selected based on the highest score. Predicted protein sequences for each genome were downloaded either from NCBI or the SEED database (Overbeek, 2005). Predicted protein sequences from the selected representative genomes $(N=18)$ were compared with the VF database (http://www.mgc. ac.cn/VFs/; Chen, 2004) using BLASTP (Altschul et al., 1990), $E$-value $<\mathrm{e}^{-4}$ ). The number of putative VFs per genome was enumerated based on the best blast hit (lowest $E$-value) for each significant protein sequence similar to the VF database.

\section{Statistical analyses}

Rates of change in DOC and bacterioplankton carbon were calculated by dividing the difference between start and end concentrations by the incubation duration. Bacterioplankton abundance was converted to carbon units assuming $20 \mathrm{fg} \mathrm{C}$ per cell (Lee and Fuhrman, 1987), and DOC in the dark dilution cultures was calculated by subtracting bacterial carbon from measured total organic carbon in water samples. Bacterioplankton-specific growth rates were calculated as the natural log change in cell abundance over the period of loglinear growth (roughly 8-30 hours of the incubations). Bacterial growth efficiency was calculated as the ratio of bacterial carbon production (rate of increase in bacterial carbon) to rate of DOC removal. Averageneighbor clustering on OTU-weighted unifrac distances (see Supplementary Materials) was used to analyze multivariate community structure differentiation among all incubation and ambient community samples within the software package PRIMER (Version 6, Primer-E, Plymouth, UK, 2006). The similarity profile (SIMPROF) permutation routine in PRIMER was used within hierarchical clustering models to test whether individual samples differed significantly $(P<0.05)$, and analysis of similarity (ANOSIM) was used to test if communities differed among sample sets assigned to a priori treatment groupings; OTU relative abundances were used to calculate these statistics on weighted Unifrac 
distance matrices. We used ANOVA to test whether mean relative abundances of specific phylotypes and OTUs differed among treatments. We controlled the false-discovery rate for multiple tests for all ANOVAs using the $q$-value statistic (Storey and Tibshirani, 2003), such that the maximum $q$-value for significance remained less than half the probability of any one test being a false positive (that is, $q<0.5 /$ number of significant tests). When ANOVAs were significant, we ran Dunnet's post hoc test to identify treatments that differed significantly from controls $(P<0.05)$. All statistics were done in the SAS programming language via the software package JMP (Version 9; SAS Institute Inc., Cary, NC, USA, 1989-2010).

\section{Results}

Initial concentrations of DOC and DCNS in exudates and controls

Mean DOC concentrations in the control treatment were comparable to those observed in ambient samples ( $\sim 70 \mu \mathrm{mol} \mathrm{Cl}^{-1}$, Table 1$)$. Initial DOC concentrations of the amended treatments were all significantly enriched relative to the control treatment (Dunnet's $P<0.05$; Table 1), with Turbinaria and Amansia significantly higher than Porites and Halimeda (Tukey's post hoc test $\alpha=0.05$ ). Concentrations of DCNS within the control and ambient treatments were roughly equivalent (3.6 and $4.2 \mu \mathrm{mol} \mathrm{Cl} \mathrm{Cl}^{-1}$, respectively; Table 1). Exudates from Turbinaria were the only exudates where initial DCNS concentrations and DCNS yield were significantly higher than the control (Table 1; Dunnet's $P<0.05$ ).

All four exudates clustered separately from ambient and control waters in terms of the concentrations of DCNS components, with replicates from each exudate clustering together (Figure 1a). In control and ambient samples, the mole \% of glucose, mannose + xylose and galactose collectively accounted for $\geqslant 70 \%$ of the DCNS pool $(30 \%, 25 \%$ and $22 \%$ of total DCNS concentrations, respectively), whereas the mole \% of fucose, rhamnose and arabinose accounted for the remaining $30 \%$ of total DCNS (Table 1). Exudates from the macroalgae were all enriched significantly in rhamnose, galactose and mannose + xylose relative to either the control treatments or the ambient waters (Dunnet's $P<0.05$; Table 1). Turbinaria exudates were significantly enriched in fucose ( $43 \%$ vs $9 \%$ in controls) and depleted in both glucose $(12 \%$ vs $30 \%$ in controls) and rhamnose (3\% vs $10 \%$ in controls; Dunnet's $P<0.05)$. Exudates from Amansia were significantly enriched in galactose $(32 \%$ vs $22 \%$ in controls) and similarly depleted in glucose (14\% vs $30 \%$ in controls; Table 1).

\section{Bacterioplankton growth rates and efficiencies}

Bacterioplankton-specific growth rates were significantly higher only in the Amansia amendments (1.11 per day), whereas other treatments and controls ranged from 0.65 to 0.32 per day (Table 2; ANOVA $P=0.0005$; Tukey's post hoc test $\alpha=0.05$ ); replicate growth curves are shown in Supplementary Figure S2. Bacterioplankton carbon-accumulation rates were also the highest in the Amansia amendment treatments and the lowest in the Porites and control incubations (Table 2; ANOVA $P<0.0001$; Tukey's post hoc test $\alpha=0.05$ ). DOC drawdown rates were greater in both Turbinaria and Amansia exudate treatments compared with those of Halimeda and Porites and the control incubations (Table 2). As a result, bacterioplankton growing on Turbinaria exudates exhibited the lowest bacterial growth efficiency (0.06) compared with other exudate treatments $(0.12-0.20)$, significantly lower than the control treatments (0.27; Dunnet's $P<0.05)$.

\section{Exudate DCNS composition and bacterioplankton selective removal}

We analyzed the composition and selective removal of just the exuded portion of the DOM pool by subtracting concentrations of DOC and DCNS sugar components in the control from those in the exudate treatments at each time point (Table 3); the difference between control and exudate treatment is the

Table 1 Mean DOC and DCNS concentrations in exudates, controls, and ambient reef water at the start of each experiment

\begin{tabular}{lcccccccc}
\hline Treatment & $\begin{array}{c}\text { DOC } \\
\left(\mu \mathrm{mol} \mathrm{Cl}^{-1}\right)\end{array}$ & $\begin{array}{c}\text { DCNS } \\
\left(\mu \mathrm{mol} C l^{-1}\right)\end{array}$ & $\begin{array}{c}\text { DCNS } \\
\text { yield }\end{array}$ & $\begin{array}{c}\text { Mole } \% \\
\text { fucose }\end{array}$ & $\begin{array}{c}\text { Mole } \% \\
\text { rhamnose }\end{array}$ & $\begin{array}{c}\text { Mole } \% \\
\text { arabinose }\end{array}$ & $\begin{array}{c}\text { Mole } \% \\
\text { galactose }\end{array}$ & $\begin{array}{c}\text { Mole } \% \\
\text { glucose }\end{array}$ \\
\hline mannose + xylose
\end{tabular}

Abbreviations: DCNS, dissolved combined neutral sugar; DOC, dissolved organic carbon.

DCNS yield is calculated as the molar ratio of DCNS carbon to total DOC. Mole \% values are the ratio of each sugar concentration to the total DCNS concentration in moles of carbon (see Figure 1a for raw concentrations of each sugar). Each entry is the mean and s.d. of two replicate incubations (one Porites replicate was excluded from DCNS calculations as an outlier; see Figure 3). Treatments that differ significantly from the control (Dunnet's $P<0.05$ ) are emphasized in bold italics. 
amount of exuded DOC/DCNS released by the coral or alga above the recalcitrant background pool, and the change over the 48-h incubation is the amount of that exudate fraction used by bacterioplankton. The DCNS yields (DCNS:DOC) of the various exudates ranged from $56 \%$ in the Porites exudates to just $8 \%$ in the Amansia exudates (Table 3), all higher than the background control and ambient DCNS yields of 5-6\% (Table 1). Turbinaria exudates contained significantly more fucose, and Amansia exudates

\section{a Starting DCNS concentration $\left(\mu \mathrm{mol} \mathrm{C} \mathrm{L}^{-1}\right)$}
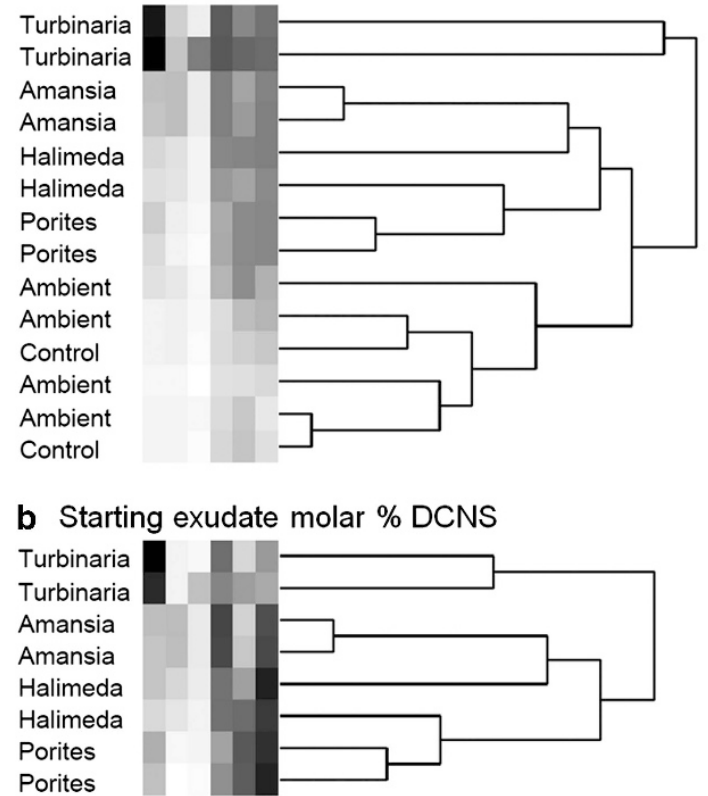

\section{c Exudate DCNS removed in $48 \mathrm{~h}(\mu \mathrm{mol} \mathrm{C} \mathrm{L}-1)$}
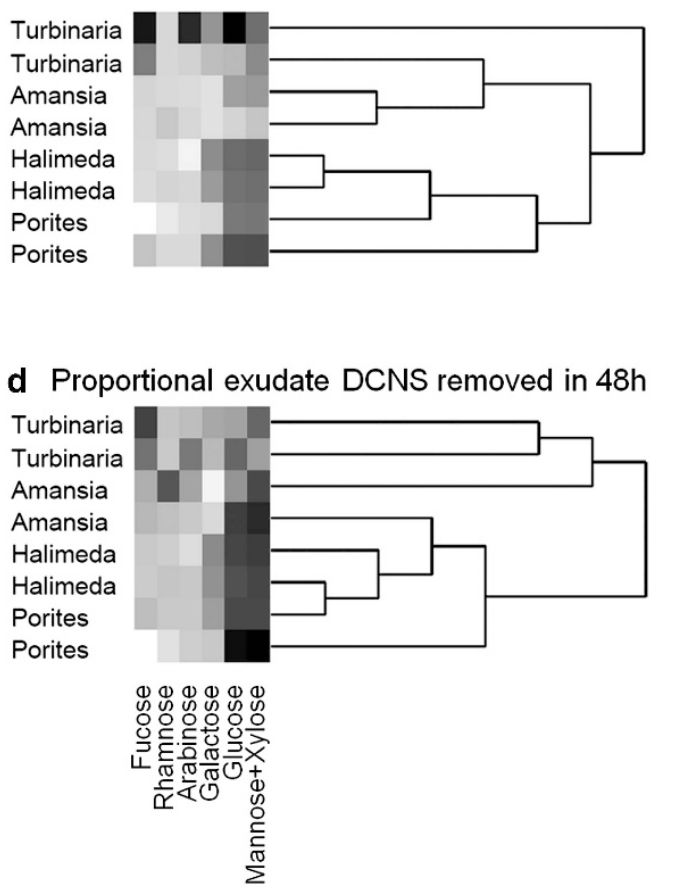

contained significantly more galactose and rhamnose than the other treatments (Figure 1b, ANOVA $P<0.01$, Tukey's post hoc test $\alpha=0.05$ ).

After the 48-h incubation period, DCNS yields declined or remained similar in all four treatments (Table 3). The DCNS yield of the portion of the DOM used during the incubation ranged widely, with bacterioplankton exclusively using DCNS from the Porites exudates (DCNS yield of exudate removed of $104 \%$ ), using primarily DCNS in the Halimeda and Turbinaria treatments (78\% and 49\%, respectively) and using near-negligible DCNS from the Amansia exudates (5\%). Among the individual sugar components of DCNS, bacterioplankton preferentially consumed glucose and mannose +xylose in the Halimeda and Porites exudate treatments, preferentially consumed fucose in the Turbinaria exudate treatments and used all sugar components roughly equally in the Amansia exudate treatments (Figure 1c). Proportionally, bacterioplankton consumed $\sim 20-50 \%$ of the glucose and mannose + xylose in all exudates and an equal amount of the fucose in the Turbinaria exudates, but showed variable percent removal in other exudate sugar components ranging from 0 to $\sim 15 \%$ over the 48 -h incubation (Figure 1d).

\section{Bacterial community differentiation}

To visualize how broad family-level clades varied among the treatments after $48 \mathrm{~h}$ incubation, we generated a relative enrichment profile heatmap by standardizing the abundances of each clade to the clade's mean abundance across all pooled samples (Figure 2). To test the significance of multivariate phylogenetic differentiation among samples and treatments, we generated an average-neighbor heirarchical dendrogram from weighted unifrac distances (Figure 2, top; see Supplementary Materials for bioinformatic details). Samples clustered significantly by treatment, with no significant difference among replicate incubations within each treatment (SIMPROF $P>0.05$; Figure 2). These

Figure 1 Starting composition and selective bacterial removal of each of the six neutral sugar hydrolysis products (DCNS) among coral and algal exudate treatments. Experimental treatments are average-neighbor clustered according to DCNS composition. (a) The starting concentration of each sugar component of DCNS among treatments and controls. (b) The mole \% of each sugar in starting exudates after control correction. (c) The change in concentration of each sugar component of DCNS in exudates over $48 \mathrm{~h}$ after control correction. (d) The mole \% of each sugar in the utilized portion of each exudate (that is, starting-remaining) after control correction. Note that exudates clustered according to source both in terms of absolute concentration (a) and in terms of relative contribution (b) at the start of the experiment, and all exudates were clearly distinct from control treatments and ambient reef water collected at the start of the experiment. Note also that utilization profiles of exudates by bacterioplankton differed according to treatment both in terms of absolute concentrations removed (c) and in terms of proportional removal of exuded DCNS components (d). 
Table 2 Changes in DOC, DCNS, and bacterial growth efficiency over the duration of $48 \mathrm{~h}$ seawater cultures

\begin{tabular}{|c|c|c|c|c|c|}
\hline Treatment & $\begin{array}{l}\text { DOC change } \\
\left(\mu \mathrm{mol} C 1^{-1}\right)\end{array}$ & $\begin{array}{l}\text { DCNS change } \\
\left(\mu \mathrm{mol} C 1^{-1}\right)\end{array}$ & $\begin{array}{l}\text { Bact. C change } \\
\left(\mu \mathrm{mol} C l^{-1}\right)\end{array}$ & $\begin{array}{c}\text { Bacterial specific } \\
\text { growth rate (per day) }\end{array}$ & Bacterial growth efficiency \\
\hline Turbinaria & $-21.5 \pm 1.3$ & $-7.89 \pm 8.76$ & $1.25 \pm 0.08$ & $0.61 \pm 0.03$ & $0.06 \pm 0.01$ \\
\hline Amansia & $-23.9 \pm 1.6$ & $0.52 \pm 0.61$ & $2.86 \pm 0.07$ & $1.11 \pm 0.01$ & $0.12 \pm 0.01$ \\
\hline Halimeda & $-7.7 \pm 1.5$ & $-3.01 \pm 0.25$ & $1.46 \pm 0.38$ & $0.65 \pm 0.11$ & $0.20 \pm 0.08$ \\
\hline Porites & $-2.8 \pm 2.0$ & -1.09 & $0.42 \pm 0.15$ & $0.35 \pm 0.08$ & $0.18 \pm 0.08$ \\
\hline Control & $-1.6 \pm 0.3$ & $1.56 \pm 3.12$ & $0.43 \pm 0.02$ & $0.41 \pm 0.15$ & $0.27 \pm 0.04$ \\
\hline
\end{tabular}

Abbreviations: Bact. C, bacterial carbon; DCNS, dissolved combined neutral sugar; DOC, dissolved organic carbon.

Each entry is the mean and s.d. of two replicate incubations (one Porites DCNS replicate was excluded from mean calculations as an outlier; see Figure 3). Treatments that differ significantly from the control (Dunnet's $P<0.05$ ) are emphasized in bold italics.

Table 3 Compositional characteristics of exudates and proportional removal of exudates over the duration of $48 \mathrm{~h}$ seawater cultures

\begin{tabular}{lccccc}
\hline Treatment & $\begin{array}{c}\text { Starting exudate } \\
\text { DCNS yield }\end{array}$ & $\begin{array}{c}\text { Remaining exudate } 48 \mathrm{~h} \\
\text { DCNS yield }\end{array}$ & $\begin{array}{c}\text { Exudate removed } 48 \mathrm{~h} \\
\text { DCNS yield }\end{array}$ & $\begin{array}{c}\text { \% Change in exuded } \\
\text { DCNS }\end{array}$ & $\begin{array}{c}\% \text { Change in } \\
\text { exuded DOC }\end{array}$ \\
\hline Turbinaria & $33 \% \pm 8 \%$ & $30 \% \pm 0 \%$ & $-49 \% \pm 47 \%$ & $-19 \% \pm 20 \%$ & $-19 \% \pm 1 \%$ \\
Amansia & $8 \% \pm 0 \%$ & $9 \% \pm 1 \%$ & $-5 \% \pm 2 \%$ & $6 \% \pm 7 \%$ & $-22 \% \pm 1 \%$ \\
Halimeda & $14 \% \pm 7 \%$ & $5 \% \pm 7 \%$ & $-78 \% \pm 16 \%$ & $-54 \% \pm 20 \%$ & $-18 \% \pm 4 \%$ \\
Porites & $56 \%$ & $34 \%$ & $-104 \%$ & $-24 \%$ & $-45 \% \pm 10 \%$
\end{tabular}

Abbreviations: DCNS, dissolved combined neutral sugar; DOC, dissolved organic carbon.

Exudate concentrations are calculated after subtracting the control concentrations of DOC and DCNS from each exudate treatment (see Figure 1c for raw concentrations and Figure $1 \mathrm{~d}$ for mol \% of each sugar in the exuded fraction). DCNS yields are reported for starting exudates (treatmentcontrol at time zero), remaining exudates (treatment-control after $48 \mathrm{~h}$ incubation) and the exudate removed (remaining-starting). Proportional removal (\% change) of exuded DOC and DCNS is calculated as the ratio of the 48-h change in exudate concentration to the starting exudate concentration. Each entry is the mean and s.d. of two replicate incubations (one Porites DCNS replicate was excluded from mean calculations as an outlier; see Figure 1).

patterns of significant treatment differentiation were maintained using clade/phylotype relative abundances as well (ANOSIM $P<0.001$, Global $R=0.92$ ), with each treatment differing significantly from both the ambient environment (ANOSIM pairwise $P<0.02$ ) and from the control incubations (ANOSIM pairwise $P<0.03$ ). Samples in both Turbinaria and Porites treatments were significantly different from all other treatments (SIMPROF $P<0.05$, Figure 2); there was no significant difference between communities from the Halimeda and Amansia exudate treatments (SIMPROF $P>0.05$; Figure 2).

To identify which clades drove these differences in community structure, we ran individual ANOVAs on each clade (25 tests total), comparing the four treatments $(n=3$ each) with unamended control incubations $(n=4)$ and ambient samples $(n=6)$. For each significant ANOVA (14 out of 25 tests run, $P<0.03, \quad q<0.01<0.5 / 14)$, we used Dunnet's post hoc test to determine which treatments had higher relative abundances than the unamended controls $\quad(P<0.05)$. Community differentiation among the exudate amendment treatments was driven by nine clades that exhibited significant differences among the treatments and relative to the controls (Figure 2 and bold and underlined values in Table 4). Exudates from the Turbinaria treatment increased the proportion of sequences belonging to the Gammaproteobacteria families Vibrionaceae and Pseudoalteromonadaceae. Exudates from Amansia and Halimeda treatments increased the relative abundance of the alphaproteobacterial family Rhodobacteraceae, and Halimeda exudate treatment additionally stimulated enrichment of the Flavobacterial family Cryomorphaceae.

Five families were enriched in the Porites exudate treatment, including the Alphaproteobacteria families Erythrobacteraceae, Kordiimonadaceae, Hyphomonadaceae and Sneathiellaceae, the Bacteriovoraceae family of the Deltaproteobacteria and the Planctomycete clade OM190 (Figure 2; Table 4). In addition to these nine clades that were enriched in the exudate amendments, four clades were significantly different in the ambient environment relative to the experimental treatments and unamended controls: SAR11 and Synechococcus were enriched in ambient waters, and the proteobacterial families Rhodobacteraceae and Alteromonadaceae were reduced in ambient waters compared with controls (Figure 2; Table 4). In addition, the betaproteobacterial family Methylophilaceae was significantly enriched in the Porites exudate and unamended control treatments $(4.95 \%$ and $6.30 \%$, respectively) relative to other treatments and the ambient water.

\section{Bacterial population enrichment}

We further examined diversity and enrichment profiles of specific bacterial taxa at the level of 


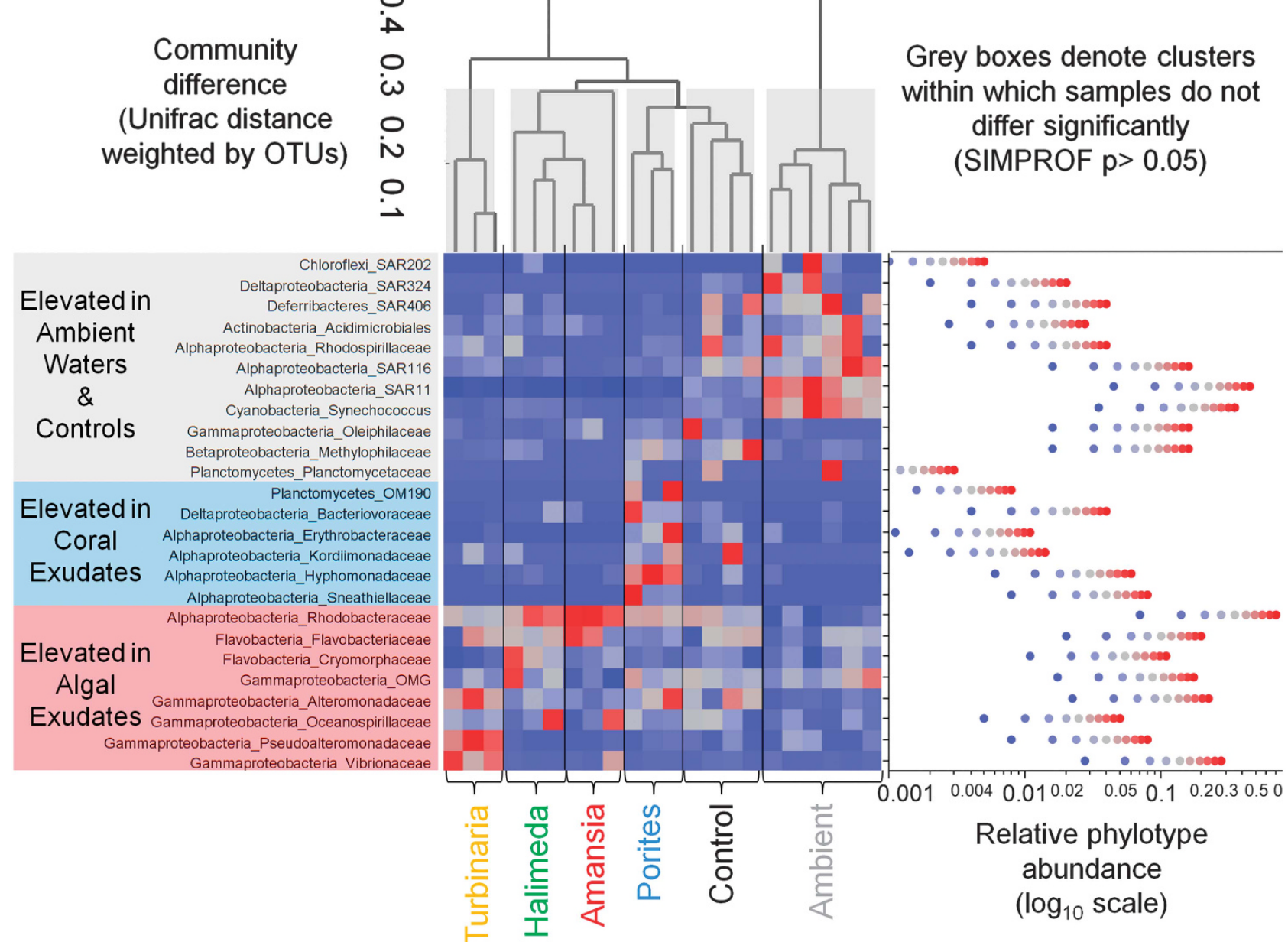

Figure 2 Heirarchical clustering of samples according to bacterial community similarity, with heatmap showing relative enrichment of family-level clades among samples. At top is an average-neighbor cluster dendrogram built from OTU-weighted Unifrac distances, with gray boxes surrounding samples that cluster and do not differ significantly (SIMPROF $P>0.05$ ). Note that communities in replicate incubations within treatments do not differ, whereas treatments differ significantly from each other and from controls and ambient water, except Halimeda and Amansia —amended communities that do not differ significantly. The adjacent heatmap shows relative abundance of each family-level clade in each sample. Heatmap data are standardized by clade to show relative enrichment among treatments; colorcoding for relative abundance is shown in the right-hand plot for each clade. Mean relative abundance data and statistical comparisons are provided in Table 4.

OTUs (defined as clusters of sequences averaging $>95 \%$ identity). A collapsed maximum-likelihood tree summarizing the phylogenetic identities of all OTUs was found in this study, and their nearest neighbors in the SILVA SSU reference database is shown in Figure 3, with specific taxa highlighted according to treatments in which they were enriched (a complete (uncollapsed) version of this tree can be found in the Supplementary Information (Supplementary Figure S3), along with a summary of the 15 most abundant OTUs in each treatment at harvest (Supplementary Table S4)).

To identify those OTUs enriched in specific treatments, we compared mean relative abundances of each OTU $(n=180)$ among all four treatments and the control incubations using ANOVAs (Supplementary Table S5). For each significant OTU ANOVA $(n=27)$, we used Dunnet's post hoc test to determine which treatments were enriched significantly relative to the controls $(n=18$, Figure $3, P<0.035, q<0.018<0.5 / 27$ ). Table 5 lists all of these OTUs and their nearest genomic isolate representatives (see VF analysis below). To place these highlighted OTUs of interest in more detailed phylogenetic context, we built a maximum-likelihood tree from each OTU and the three nearest cultured isolates (Supplementary Figure S6) derived from $16 \mathrm{~S}$ databases as described above and in the Supplementary Materials. Analyses of OTU diversity (richness and evenness) showed that richness was the highest on ambient water, and Porites exudates with both richness and evenness reduced significantly in the Amansia exudate treatments (see Supplementary Results, Supplementary Table S8 and Supplementary Figure S9). Of the other nine significant ANOVA results, six OTUs were most 
Table 4 Clade mean relative abundances among treatments with significance tests

\begin{tabular}{|c|c|c|c|c|c|c|c|c|}
\hline \multirow[t]{2}{*}{ Clade (ordered by Figure 2) } & \multicolumn{2}{|c|}{ ANOVA $F_{5,21}$} & \multirow[b]{2}{*}{ Turbinaria } & \multicolumn{4}{|c|}{ Mean relative abundance in each treatment } & \multirow[b]{2}{*}{ Ambient } \\
\hline & P-value & q-value & & Halimeda & Amansia & Porites & Control & \\
\hline Chloroflexi_SAR202 & 0.364 & 0.080 & $0.00 \%$ & $0.04 \%$ & $0.00 \%$ & $0.00 \%$ & $0.00 \%$ & $0.13 \%$ \\
\hline Deltaproteobacteria_SAR324 & 0.150 & 0.041 & $0.00 \%$ & $0.00 \%$ & $0.00 \%$ & $0.00 \%$ & $0.07 \%$ & $0.42 \%$ \\
\hline Deferribacteres_SAR 406 & 0.080 & 0.025 & $0.05 \%$ & $0.23 \%$ & $0.00 \%$ & $0.03 \%$ & $0.60 \%$ & $0.77 \%$ \\
\hline Actinobacteria_Acidimicrobiales & 0.310 & 0.078 & $0.21 \%$ & $0.30 \%$ & $0.24 \%$ & $0.06 \%$ & $0.54 \%$ & $0.93 \%$ \\
\hline Alphaproteobacteria_Rhodospirillaceae & 0.118 & 0.034 & $0.59 \%$ & $0.38 \%$ & $0.00 \%$ & $0.18 \%$ & $0.83 \%$ & $1.47 \%$ \\
\hline Alphaproteobacteria_SAR116 & 0.014 & 0.006 & $1.40 \%$ & $0.72 \%$ & $0.06 \%$ & $0.92 \%$ & $4.25 \%$ & $5.77 \%$ \\
\hline Alphaproteobacteria_SAR11 & 0.000 & 0.000 & $1.21 \%$ & $1.70 \%$ & $1.13 \%$ & $2.46 \%$ & $7.48 \%$ & $21.50 \%$ \\
\hline Cyanobacteria_Synechococcus & 0.000 & 0.000 & $\overline{0.79 \%}$ & $3.33 \%$ & $\overline{0.96 \%}$ & $1.10 \%$ & $4.02 \%$ & $\overline{23.20 \%}$ \\
\hline Gammaproteob̄acteria_Oleiphilaceae & 0.347 & 0.080 & $0.40 \%$ & $0.22 \%$ & $2.16 \%$ & $1.65 \%$ & $4.37 \%$ & $\overline{0.13 \%}$ \\
\hline Betaproteobacteria_Methylophilaceae & 0.026 & 0.010 & $0.44 \%$ & $1.37 \%$ & $0.00 \%$ & $4.95 \%$ & $6.30 \%$ & $0.86 \%$ \\
\hline Planctomycetes_Planctomycetaceae & 0.884 & 0.178 & $\overline{0.00 \%}$ & $0.00 \%$ & $\overline{0.00 \%}$ & $0.03 \%$ & $0.04 \%$ & $\overline{0.05 \%}$ \\
\hline Planctomycetes_OM190 & 0.009 & 0.004 & $0.00 \%$ & $0.00 \%$ & $0.00 \%$ & $0.18 \%$ & $0.00 \%$ & $0.00 \%$ \\
\hline Deltaproteobacteria_Bacteriovoraceae & 0.008 & 0.004 & $0.02 \%$ & $0.48 \%$ & $0.18 \%$ & $\overline{1.87 \%}$ & $0.27 \%$ & $0.06 \%$ \\
\hline Alphaproteobacteria_Erythrobacteraceae & 0.009 & 0.004 & $0.02 \%$ & $0.00 \%$ & $0.00 \%$ & $\overline{0.51 \%}$ & $0.13 \%$ & $0.05 \%$ \\
\hline Alphaproteobacteria_Kordiimonadaceae & 0.364 & 0.080 & $0.18 \%$ & $0.13 \%$ & $0.00 \%$ & $\overline{0.49 \%}$ & $0.34 \%$ & $0.00 \%$ \\
\hline Alphaproteobacteria_Hyphomonadaceae & 0.000 & 0.000 & $0.07 \%$ & $0.30 \%$ & $0.13 \%$ & $3.65 \%$ & $0.42 \%$ & $0.07 \%$ \\
\hline Alphaproteobacteria_Sneathiellaceae & 0.029 & 0.010 & $0.00 \%$ & $0.00 \%$ & $0.00 \%$ & $\overline{3.50 \%}$ & $0.11 \%$ & $0.00 \%$ \\
\hline Alphaproteobacteria_Rhodobacteraceae & 0.000 & 0.000 & $32.96 \%$ & $51.08 \%$ & $62.98 \%$ & $4 \overline{1.37 \%}$ & $34.50 \%$ & $9.78 \%$ \\
\hline Flavobacteria_Flavobacteriaceae & 0.263 & 0.069 & $8.80 \%$ & $10.27 \%$ & $12.67 \%$ & $5.13 \%$ & $8.52 \%$ & $5.83 \%$ \\
\hline Flavobacteria_Cryomorphaceae & 0.002 & 0.001 & $1.14 \%$ & $\underline{7.30} \%$ & $3.01 \%$ & $2.06 \%$ & $2.37 \%$ & $2.69 \%$ \\
\hline Gammaproteobacteria_OMG & 0.083 & 0.025 & $4.88 \%$ & $\overline{9.38 \%}$ & $1.94 \%$ & $8.11 \%$ & $7.62 \%$ & $7.66 \%$ \\
\hline Gammaproteobacteria_Alteromonadaceae & 0.002 & 0.001 & $13.59 \%$ & $4.60 \%$ & $2.77 \%$ & $10.58 \%$ & $7.90 \%$ & $1.15 \%$ \\
\hline Gammaproteobacteria_Oceanospirillaceae & 0.741 & 0.156 & $1.35 \%$ & $1.96 \%$ & $1.59 \%$ & $1.22 \%$ & $1.38 \%$ & $\overline{0.63 \%}$ \\
\hline Gammaproteobacteria_Pseudoalteromonadaceae & 0.000 & 0.000 & $3.19 \%$ & $0.04 \%$ & $0.06 \%$ & $0.21 \%$ & $0.25 \%$ & $0.44 \%$ \\
\hline Gammaproteobacteria_Vibrionaceae & 0.000 & 0.000 & $\overline{21.21 \%}$ & $0.12 \%$ & $5.81 \%$ & $0.33 \%$ & $0.57 \%$ & $0.38 \%$ \\
\hline
\end{tabular}

Abbreviation: ANOVA, analysis of variance.

ANOVA $P / q$-values in bold italic are significant after multiple comparison controls on the false-discovery rate (see Materials and methods and Results). Mean relative abundances significantly different from control treatments (Dunnet's $P<0.05$ ) are underlined; those in bold are higher, whereas those in italics are lower than control cultures.

abundant in controls and ambient samples and are discussed in the Supplementary Materials (an additional two OTUs comprised $<0.5 \%$ of any given treatment (OTU239 and OTU52), and one showed no significant differences from the control treatments after post hoc testing (OTU8); these were not analyzed further).

The Turbinaria exudate treatments were uniquely enriched in nine OTUs (Figure 3 and Table 5), more than any other treatment, including two OTUs $>96 \%$ sequence identity to isolates of Photobacterium (OTUs 59 and 102, family Vibrionaceae), two OTUs $>92 \%$ sequence identity to isolates of Alteromonas (OTUs 39 and 18, family Alteromonadaceae), three OTUs $>90 \%$ sequence identity to isolates of Pseudoalteromonas (OTU17, OTU6 and OTU27; family Pseudoalteromonadaceae) and two OTUs belonging to the Rhodobacteraceae (OTU10094.6\% identity with Pseudoruegeria and OTU174$87.2 \%$ identity with Ruegeria). Cultures amended with exudates from Amansia and Halimeda were both enriched with OTU14 $(94.2 \%$ identity with Nautella within the Rhodobacteraceae) and two Flavobacteria (OTUs 854 and 162; 83.7\% and 86.8\% identity with Fluviicola, respectively), with levels significantly higher than the controls and either of the other two treatments.

The Porites exudate treatment enriched six taxa, most belonging to deeply branching clades within the alpha- and gamma-proteobacteria. Three taxa belonging to the alphaproteobacteria, a Hyphomonadaceae (OTU50, 92.9\% identity to Hyphomonas), an Erythrobacteracaeae (OTU197, 99.6\% identity to Erythrobacter) and a Sneathiellaceae (OTU115, $94.4 \%$ identity to Sneathiella), became notably abundant in these cultures relative to all other treatments, reaching $3.5 \%, 0.5 \%$ and $1.5 \%$ in the Porites cultures, respectively, but remaining rare in all other treatments $(<0.5 \%,<0.2 \%$ and $<0.01 \%$, respectively). One OTU belonging to the Rhodobacteraceae (OTU173-90.2\% identity to Thalassobius) also showed enrichment but remained relatively rare in the Porites cultures. Two taxa belonging to deeply branching clades of the gammaproteobacterial family Alteromonadaceae (OTU136-91.4\% identity to Cellvibrio and OTU642-93.3\% identity to Haliea) were also significantly enriched in cultures amended with Porites exudates.

VFs in genomes of closely related isolates

We compared the mean number of VFs found in the most closely related isolate with a sequenced genome to each OTU enriched in each exudate treatment and/or relatively enriched in the ambient waters (because few OTUs were enriched in the Amansia and Halimeda exudate treatments and the communities did not differ significantly—see 


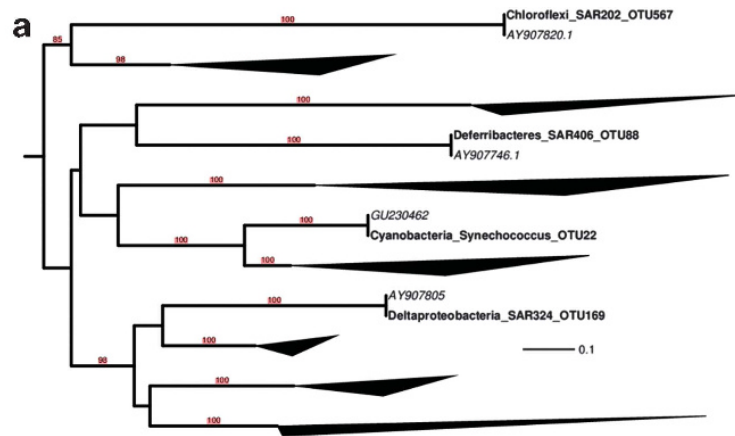

Chloroflexi - SAR202 (1 OTU)

Actinobacteria - Acidimicrobiales (4 OTUs)

Bacteriodetes - Flavobacteria (see Panel c)

Deferribacteres - SAR406 (1 OTU)

Planctomycetes (2 OTUs)

Cyanobacteria - Synechococcus (1 OTU)

Cyanobacteria - Chloroplasts (4 OTUs)

Deltaproteobacteria - SAR324 (1 OTU)

Alphaproteobacteria (see Panel b)

Deltaproteobacteria - Bacteriovoraceae (4 OTUs)

Gammaproteobacteria (see Panel d)

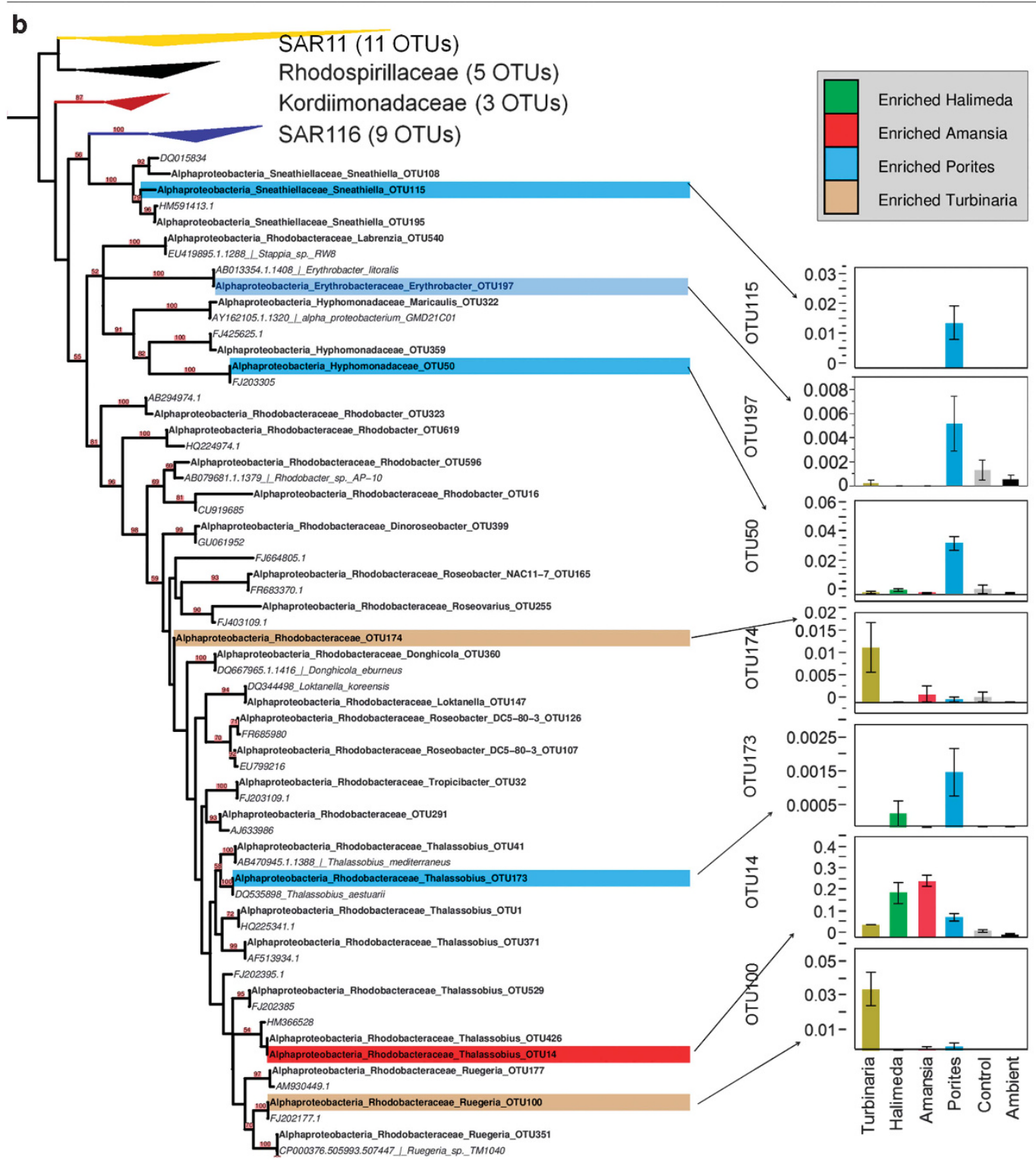

Figure 3 Maximum-likelihood phylogeny of all OTUs analyzed in this study scaffolded with the nearest neighbors from the SILVA RefSeq database, with OTUs showing significant differences among treatments highlighted and mean relative abundances graphed. (a) A complete phylogeny is shown, with clades collapsed and annotated according to the number of OTUs found among all samples. (b-d) Expansion phylogenies of the Alphaproteobacteria (b), Flavobacteria (c) and Gammaproteobacteria (d) are shown. OTUs identified by ANOVA and Dunnet's test as being significantly enriched in one of the exudate treatments relative to the controls are highlighted with a colored bar according to the treatment in which they were enriched. Arrows link each significant OTU with a graph comparing relative abundances among treatments (whiskers are 1 s.e. of the mean). OTUs from this study are in bold, whereas the nearest neighbors used for scaffolding the tree are listed in italics. Note that confidence values $>60$ (of 100 bootstraps) are annotated above branches. A scale bar showing evolutionary distance according to the generalised time-reversible (GTR) model is shown in (a). See Supplementary Information for a complete phylogeny (Supplementary Figure S3) and a table of statistical tests and mean relative abundances (Supplementary Table S5). 

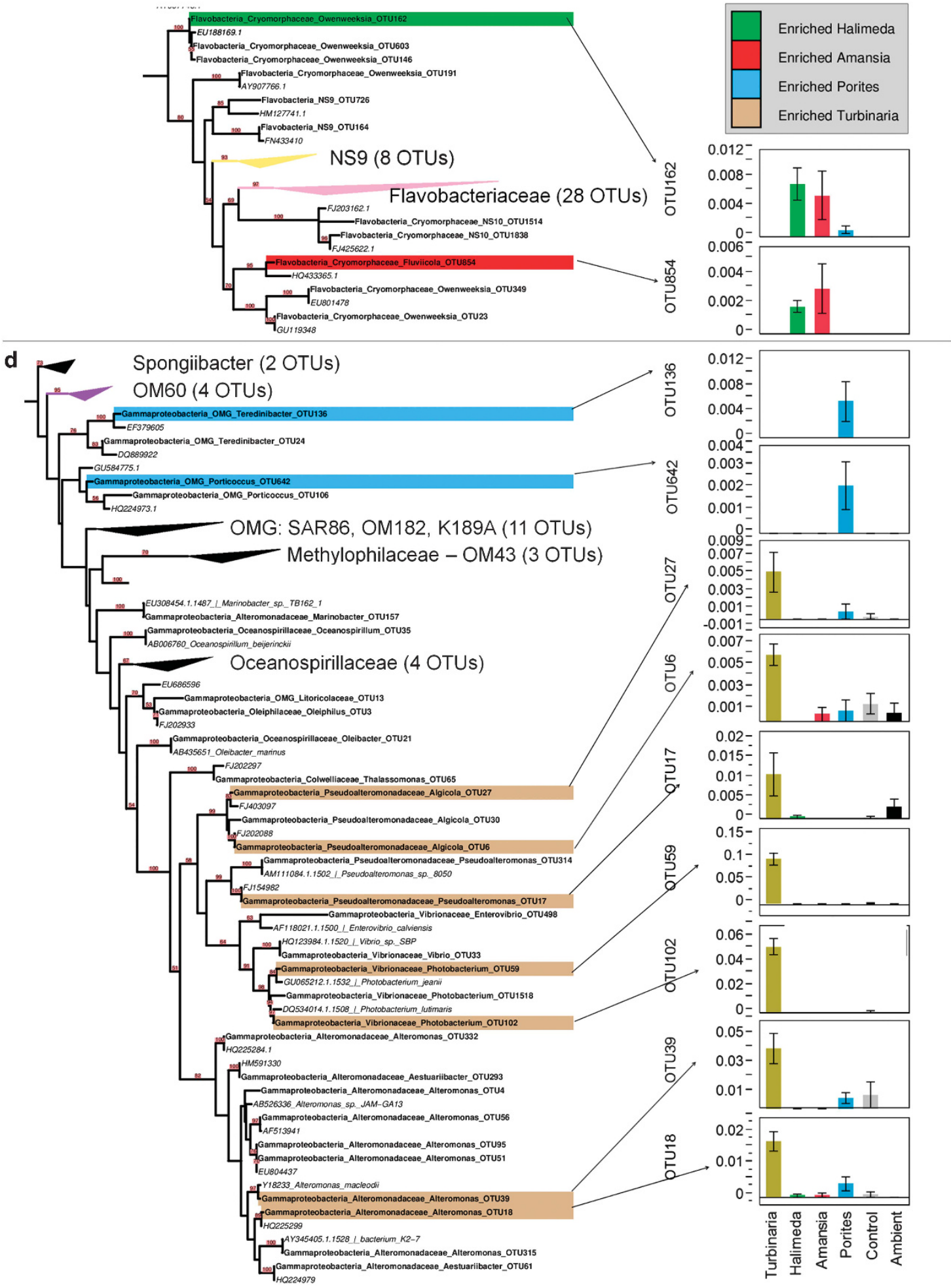

Figure 3 (Continued).

Figure 2-we combined these treatments to allow statistical testing). We found significant differences among treatments (ANOVA $P<0.001$ ), with post hoc testing revealing that Turbinaria exudates select for populations with the highest potential mean VFs per genome, significantly greater than those selected for by coral exudates, with Ambient populations having significantly fewer potential VFs per genome than all experimental treatments (Figure 4; Tukey's post hoc test $\alpha=0.05$ ). 
Table 5 OTUs enriched in specific treatments, the nearest related isolate genome and number of VFs

\begin{tabular}{|c|c|c|c|c|c|}
\hline Treatment Enriched & OTU & Phylum/class & Best genomic match & $\% I D$ & $\# V F s$ \\
\hline Amansia & OTU854 & Flavobacteria & Fluviicola taffensis DSM 16823 & 88 & 541 \\
\hline $\mathrm{Amn} / \mathrm{Hal}^{\mathrm{a}}$ & OTU14 & $\alpha$-Proteobacteria & Ruegeria spp. TM1040 & 91 & 672 \\
\hline Halimeda & OTU162 & Flavobacteria & Fluviicola taffensis DSM 16823 & 84 & 541 \\
\hline Porites & OTU173 & $\alpha$-Proteobacteria & No genome $>80 \%$ identity & NA & NA \\
\hline Porites & OTU136 & $\gamma$-Proteobacteria & Cellvibrio japonicus Ueda107 & 91 & 750 \\
\hline Porites & OTU50 & $\alpha$-Proteobacteria & Hyphomonas neptunium & 92 & 559 \\
\hline Porites & OTU642 & $\gamma$-Proteobacteria & Congregibacter litoralis KT71 & 92 & 652 \\
\hline Porites & OTU115 & $\alpha$-Proteobacteria & Micavibrio aeruginosavorus & 85 & 390 \\
\hline Porites & OTU197 & $\alpha$-Proteobacteria & Erythrobacter litoralis & 99 & 430 \\
\hline Turbinaria & OTU6 & $\gamma$-Proteobacteria & Pseudoalteromonas spp. SM9913 & 91 & 727 \\
\hline Turbinaria & OTU27 & $\gamma$-Proteobacteria & Pseudoalteromonas spp. SM9913 & 92 & 727 \\
\hline Turbinaria & OTU39 & $\gamma$-Proteobacteria & Alteromonas spp. SN2 & 93 & 789 \\
\hline Turbinaria & OTU18 & $\gamma$-Proteobacteria & Alteromonas macleodii & 93 & 759 \\
\hline Turbinaria & OTU59 & $\gamma$-Proteobacteria & Vibrio splendidus LGP32 & 93 & 875 \\
\hline Turbinaria & OTU102 & $\gamma$-Proteobacteria & Vibrio splendidus LGP32 & 93 & 875 \\
\hline Turbinaria & OTU174 & $\alpha$-Proteobacteria & Ruegeria pomeroyi DSS-3 & 87 & 690 \\
\hline Turbinaria & OTU100 & $\alpha$-Proteobacteria & Ruegeria spp. TM1040 & 93 & 672 \\
\hline Turbinaria & OTU17 & $\gamma$-Proteobacteria & Pseudoalteromonas spp. SM9913 & 95 & 727 \\
\hline Ambient & OTU43 & $\alpha$-Proteobacteria & Pelagibacter ubique HTCC1062 & 89 & 240 \\
\hline Ambient & OTU9 & $\alpha$-Proteobacteria & Pelagibacter ubique HTCC1062 & 97 & 240 \\
\hline Ambient & OTU38 & Flavobacteria & Fluviicola taffensis DSM 16823 & 87 & 541 \\
\hline Ambient & OTU22 & Cyanobacteria & Synechococcus spp. CC9605 & 96 & 289 \\
\hline Ambient & OTU15 & $\alpha$-Proteobacteria & No genome $>80 \%$ identity & NA & NA \\
\hline
\end{tabular}

Abbreviations: ID, identity; NA, not applicable; OTU, operational taxonomic unit; VF, virulence factor.

${ }^{a}$ OTU14 was enriched in both Amansia and Halimeda treatments. Queries all $>250$ bp and expect scores all $<\mathrm{e}^{-} 05$.

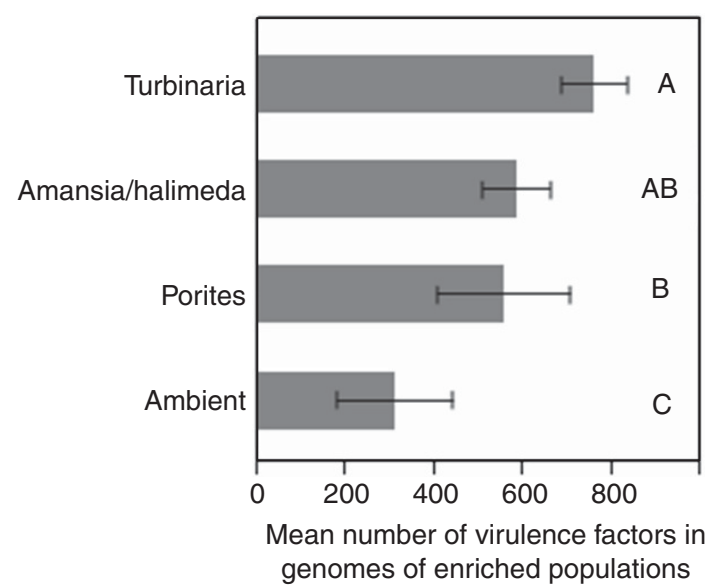

Figure 4 Differences in mean number of VFs in OTUs enriched in each exudate treatment and ambient waters based on genomes of most closely related cultured isolates. Data are listed in Table 5; whiskers are one s.e. of the mean. Representative genomes ranged from $84 \%$ to $90 \% 16 \mathrm{~S}$ sequence identity to OTUs, and statistical analysis is robust when a $90 \%$ minimum identity cutoff was applied. Note that Amansia and Halimeda exudates were combined to allow testing $(n<3$ each). Mean numbers of VFs in ambient waters are significantly lower than all three exudates, and Porites is significantly lower than Turbinaria (treatments with same letter are not significantly different, Tukey's post hoc test $\alpha=0.05)$.

\section{Discussion}

Our results demonstrate that both macroalgae and corals in tropical reef ecosystems exude significant DOM that varies in composition, stimulates bacterioplankton growth and differentially alters bacterial community structure (summarized in Figure 5). This work expands upon prior understanding by characterizing compositional differences among DOM exudates in a dynamic fraction of the carbohydrate pool (DCNS) and by providing a phylogenetically robust analysis of the bacterioplankton taxa differentially enriched by the various exudates. Our results shed light on the compositional differences among exudates from dominant-reef primary producers, demonstrating that all exudates are enriched in DCNS relative to the ambient waters and that exudates differ from each other in the concentrations and proportions of DCNS components (Figures 1a and b; Tables 1 and 3). By tracking the utilization of DCNS components over the course of a 2-day dark seawater culture, we demonstrate that variation in initial DOM composition, in part, selects for specific communities (Figure 2; Table 4). These specific bacterioplankton communities utilize the exudates at varying efficiencies and selectively remove specific DCNS components (Figures 1c and d; Tables 2 and 3). Finally, using $16 \mathrm{~S}$ pyrosequencing, we are able to identify specific bacteria selected for each exudate (Figure 3) and develop testable hypotheses regarding the potential for increased abundance of pathogenic genes in populations enriched by macroalgal exudates (Figure 4; Table 5). Together, these results further our mechanistic understanding of linkages between diverse benthic macroorganisms, DOM exudate composition and complex bacterioplankton communities that influence both local coral-algal interactions and the overall functioning of tropical reef ecosystems. 


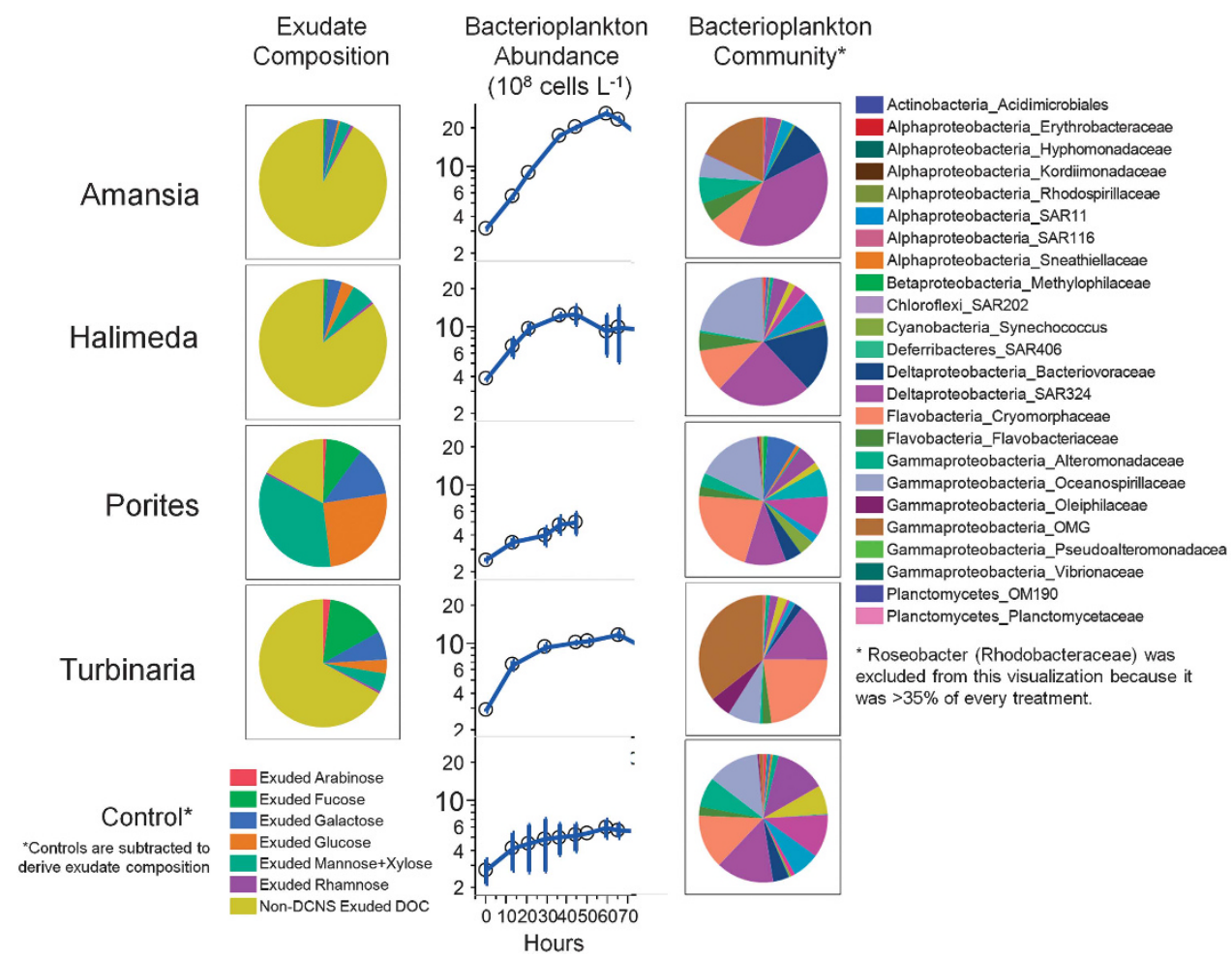

Figure 5 Summary of differences in exudate composition, subsequent bacterioplankton growth and resulting bacterial community structure among the experimental treatments. Bacterioplankton abundances are means of replicate experiments \pm 1 s.d.

\section{Macroalgal and coral DOM exudate composition and bacterioplankton utilization}

We have shown previously that fleshy macroalgae, turf algae and coral holobionts on average exude at least $10 \%$ and sometimes upwards of $35 \%$ of their daily fixed carbon as DOC, with algae releasing significantly more DOC per unit surface area than corals (Haas et al., 2011). In the present study, we show that DCNS comprise upwards of $50 \%$ of coral exudates and a smaller but still significant fraction of macroalgal exudates (8-33\%; Table 3). The DCNS fraction of DOC is clearly not the only material exuded by algae and coral, as uronic acids, proteins, amino sugars and lipids have all been detected in the tissue and DOM of algae (Percival, 1979; Jensen, 1993; Aluwihare and Repeta, 1999; Wada et al., 2007; Anastasakis et al., 2011) and the tissue and mucus of coral (Meikle et al., 1988; Coffroth, 1990; Wild et al., 2010). However, the composition of the exuded DCNS did differentiate the four exudates from both experimental controls and the ambient waters (Figure 1a), and portions of the DCNS pool were preferentially and differentially utilized by bacterioplankton among the treatments (Figures 1c and d; Tables 2 and 3), suggesting that it is a meaningful proxy for differences in the overall character of the DOM exuded by benthic macroorganisms on coral reefs.

Our results generally indicate that exudates from fleshy macroalgae are more labile than exudates from corals, with bacterioplankton growing to higher densities and consuming more DOC on exudates from the brown alga Turbinaria and the red alga Amansia (Figure 5; Table 2). We observed that fleshy macroalgae release copious amounts of DOM that can be enriched in compounds hydrolyzable to specific neutral aldoses (that is, fucose in Turbinaria and galactose in Amansia), which engenders the rapid, inefficient growth of bacterioplankton (bacterial growth efficiency $<15 \%$; Table 2), consuming both DCNS $(<20 \%)$ and other portions of the DOM pool not explicitly measured here, indicating that bacteria growing on fleshy macroalgal exudates were less selective in the removal of DCNS (Table 3). It is important to note that physiological stress due to nutrient limitation (Karl et al., 1998) or the transition between nutrient replete to nutrient deplete phases (Smith et al., 1998; Carlson, 2002) can trigger the release of DOM by phytoplankton. However, DOM release from macroalgae in nutrient replete coastal systems is also well documented (Wada et al., 2007; Chattopadhyay et al., 2010; Haas and Wild, 2010). Relative to the macroalgae, the exudates from the hermatypic coral Porites and the calcareous macroalga Halimeda were dominated by galactose, glucose and mannose + xylose, much like the composition of ambient seawater (Figures 1a and b; Table 1). On these exudates, the relatively slow, more efficient growth of bacterioplankton is largely supported by DCNS (up to $70 \%$; Table 3) and the specific utilization of these three most abundant sugars (Figures 1c and d). 
Information on the composition of DCNS within algal exudates can reveal information about the origin and macromolecular structure of a particular polysaccharide (Percival, 1979; Chattopadhyay et al., 2010; Anastasakis et al., 2011), the physiological status of the algae at the time when the exudate was harvested (Haas and Wild, 2010), or the exoenzymatic activity of the ambient community of heterotrophic bacterioplankton (Arnosti, 2011). The significant enrichment in the mole \% of fucose in the Turbinaria treatment is consistent with studies assessing the sugars in other Turbinaria species (Chattopadhyay et al., 2010) and other brown algae (Percival, 1979; Anastasakis et al., 2011), as well as in brown algal DOM exudates (Wada et al., 2007). Fucoidan is produced by Turbinaria in the cell wall to protect against desiccation (Percival, 1979; Anastasakis et al., 2011) and is a rather large macromolecule ( $\sim 50 \mathrm{kDa}$; Chattopadhyay et al. 2010). We observed significant removal of fucose from Turbinaria exudate remineralization cultures, consistent with results for the bacterial enzymatic hydrolysis of fucoidan that were conducted at comparable latitudes by Arnosti et al. (2011). Porites DOM exudates exhibited neutral sugar distributions that are consistent with those of poritid mucus origins (Coffroth, 1990). One potential mechanism by which nearly the entire DCNS pool was removed from the Porites exudate over the 2-day incubation may be that the proper combination of polysaccharide macromolecular bond structure and bacterial exo-enzymatic expression could have resulted in rapid polymer hydrolysis and subsequent bacterial substrate utilization (Arnosti, 2011).

\section{Differential growth of bacterioplankton taxa on DOM exudates of varying composition}

Our results point to a clear differentiation between the communities selected for by exudates of fleshy macroalgae and those growing on coral exudates. Although the differences in absolute magnitude of DOM released from the various benthic producers may influence community differentiation, the treatments differed not just in the relative abundance of taxa but in the specific OTUs and families selected for, suggesting that compositional differences, not just quantities, of the exuded DOM are the primary driver of community differentiation. The macroalgal exudates enriched communities in several families containing known coral pathogens, with the specific OTUs enriched closely related to potential coral pathogens with elevated numbers of putative VFs in their genomes (Figure 4; Table 5), supporting the hypothesis that these exudates may foster the growth of bacterial communities harmful to corals. In particular, exudates from Turbinaria differentially selected for OTUs within the generic clades of Vibrio/Photobacterium, Pseudoalteromonas and Alteromonas (Figure 3 and Table 5), each of which composed between $3 \%$ and $5 \%$ of the total $16 \mathrm{~S}$ reads to collectively dominate the communities (Supplementary Table S5). Each of these clades contains cultured isolates putatively associated with coral disease (Kushmaro et al., 2001; Ben-Haim et al., 2003; Costa-Ramos and Rowley, 2004; Bally and Garrabou, 2007). However, we emphasize that these VF analyses are supportive, rather than definitive evidence for the enhanced pathogenicity of algal-enriched communities.

In contrast to the algal exudates, the bacterial families and specific OTUs selected for by the coral exudates were markedly more diverse, both phylogenetically (Figure 3) and in terms of community diversity and evenness (that is, no specific OTU clearly dominated the communities as with the macroalgal exudate-selected communities, Supplementary Figure S9). The most striking enrichment was an OTU belonging to the Hyphomonadaceae family of Alphaproteobacteria (Figures 2 and 3), with close similarity to isolates of Hyphomonas and Caulobacter (Table 5; Supplementary Figure S6), which came to compose nearly $3.5 \%$ of the total 16S sequences. These OTUs belong to a group of widespread oligotrophic budding organisms found in many aquatic environments but with no evidence for pathogenicity (Stahl et al., 1992; Weiner et al., 2000; Badger et al., 2005). Other taxa enriched in the Porites exudate amendments included OTUs closely related to the Alphaproteobacteria Sneathiella and Erythrobacter and to the Gammaproteobacteria Haliea and Thalassobius, all associated with free-living oligotrophic to mesotrophic coastal marine environments and with no known pathogenic lifestyles (Koblížek et al., 2003; Jordan et al., 2007; Urios et al., 2008; Park et al., 2012). Thus, the primary organisms selectively enriched by the coral exudates are widely distributed marine bacterioplankton, with no association with pathogenic or otherwise harmful lifestyles. Nonetheless, the lack of information on the ecology of these taxa demands that additional information on their genomes be investigated before drawing further conclusions regarding their role in coral lifestyles.

\section{Ecological implications}

Conditions that enhance the competitive advantage of algae over corals, including eutrophication, overfishing or climate change, may result in benthic community phase shifts from coral to algal dominance (Done, 1992). The posited mechanisms by which algae outcompete corals under altered environmental settings (reviewed in McCook et al. (2001)) include physical disruption through shading or abrasion (Lirman, 2001; River and Edmunds, 2001), chemical-mediated competition or allelopathy (Rasher and Hay, 2010; Chadwick and Morrow, 2011) and microbial activity (Smith et al., 2006; Barott et al., 2009; Haas et al., 2011; Kelly et al., 2012). Although allelochemicals are commonly 
thought to be important drivers of coral-algal phase shifts by directly promoting algal competition over corals (Littler and Littler, 1997; Jompa and McCook, 2003; Rasher and Hay, 2010), there is an increasing experimental evidence that microbes significantly contribute to the detrimental effects of fleshy algae on corals, including demonstrations that antibiotics can ameliorate coral mortality caused by dissolved turf algal exudates (Smith et al., 2006) and reverse negative influences on coral planulae survivorship in the presence of macroalgae (Vermeij et al., 2009). Changing conditions to promote the growth of algae, which in turn release DOM that fuels microbes, is one link frequently overlooked as a mechanism that might have a negative impact on corals.

Benthic macro- and turf algae exudates have already been shown to directly stimulate microbial growth, resulting in higher abundances and biological oxygen demand (Haas et al., 2011). This elevated microbial activity may have far-reaching repercussions on corals reefs, causing hypoxia on coral surfaces, leading to coral mortality (Smith et al., 2006; Barott et al., 2009), and negatively influencing coral recruitment and recovery (Vermeij et al., 2009). The present study suggests that differences in exudate DOM composition, not solely exudate quantity, may be a proximal mechanism explaining observations that different species of algae can be more detrimental to corals than others (Jompa and McCook, 2003; Haas et al., 2009). The scale at which these exudates may have an impact on coral under various flow regimes is a critical issue demanding increased scrutiny: water retention times around algae-coral interactions on the downstream side of coral mounds may exceed 5 min (Brown, 2012), and coral mounds have been shown to deplete microbial abundance as much as a half-meter downstream (Marhaver et al., 2012). At localized scales, concentrations of bacteria can be more than 10-fold higher within the diffusive boundary layer of the corals (Brown, 2012; Marhaver et al., 2012) than in the surrounding water, and significant differences in the composition of tissue-associated microbial communities occur in these interaction zones (Barott et al., 2012). Increased algal growth has also been shown to significantly and persistently alter water chemistry and coral health both at centimeter and meter scales (Haas et al., 2009; Hauri et al., 2010; Niggl et al., 2010).

Shifts in carbon sources have been previously documented to drive increases in pathogenic microbes in coastal ecosystems. For example, cholera epidemics have been associated with blooms of phyto- and zooplankton linked to elevated nutrients in coastal runoff, which subsequently stimulate the growth of Vibrio cholerae in part, because zooplankton exoskeleton chitin serves as a carbon source for the pathogen (Colwell and Huq, 2001). In linking outbreaks of the coral disease atramentous necrosis to terrestrial runoff on the Great Barrier Reef, Haapkylae et al. (2011) found that dissolved and particulate carbon concentrations were a major statistical correlate and suggested that runoffinduced increases in primary production facilitated infections by increasing growth rates of microbes. Our results similarly support changes in carbon quality as a driver for increasing bacterioplankton growth and selection for potential pathogens on coral reefs.

Without additional culture-based work on coral pathogens, we cannot draw clear connections between the taxa selected for by algal DOM exudates and direct detrimental effects on coral health. Many of the algal exudate-enriched OTUs identified here by $16 \mathrm{~S}$ amplicon sequencing were related to cultured isolates identified as known pathogens, but closely related species and strains within bacterial generic-level clades can exhibit very different hostpathogen dynamics depending on conditions or how cellular machinery is used (Coenye and Vandamme, 2003; Jani and Cotter, 2010; Gennari et al., 2012). The evidence presented here should be interpreted as hypothesis-generating rather than definitive proof that algal exudates select for coral pathogens. Nonetheless, there is significant evidence for opportunistic pathogenicity in many bacterial lineages, particularly the copiotrophic Gammaproteobacteria taxa identified here such as Vibrio (Kushmaro et al., 2001; Ben-Haim et al., 2003; Rosenberg et al., 2007). The etiologies of marine diseases frequently cannot be determined (Rosenberg et al., 2009). Thus, polymicrobial (Carlton and Richardson, 1995; Cooney et al., 2002) and opportunist pathogens (Harvell et al., 1999) are becoming more important in our understanding of emerging diseases in the marine environment. Our results support the idea that coral-algal phase shifts result in more algal-released DOM and that these labile resources stimulate bacterioplankton growth (potentially causing localized hypoxia) and select for potential opportunistic pathogens, which may directly increase coral disease.

\section{Conclusions}

By demonstrating selective bacterial population enrichment by DOM exudates of algae and coral and linking this enrichment to compositional differences in both the exudates produced and the proportion consumed during bacterioplankton growth, our results provide a mechanism by which benthic primary producers may fuel and shape bacterial communities in coral reef ecosystems. In characterizing differences in the composition of DOM from different algae and coral and demonstrating the strong selection pressures these different DOM types place on bacterioplankton communities, we provide a clear experimental linkage between DOM quality and bacterial population structure, which can launch more targeted studies of the role of these specific relationships in reef habitats. Finally, the differences in the types of bacterioplankton enriched by the various exudates point to a 
mechanism by which algae may foster the growth of opportunistic coral pathogens as an indirect form of competition, facilitating ongoing phase shifts in tropical reef ecosystems.

\section{Acknowledgements}

We thank K Seydel for assistance with boating and SCUBA logistics in Moorea, the staff of the UC Berkeley Gump station for their logistical support, L Tomsho and the staff of the S Schuster Laboratory at Penn State University for pyrosequencing, and E Halewood and A James for their laboratory assistance with DOC measurement. This research was supported by the National Science Foundation (NSF; http://www.nsf.gov/) Moorea Coral Reef Long Term Ecological Research project (OCE0417412) and awards OCE-0927411 to CAC, OCE0927415 and DEB-1046413 to FR, and OCE-0927448 to JES were provided.

\section{References}

Altschul SF, Gish W, Miller W, Myers EW, Lipman DJ. (1990). Basic local alignment search tool. J Mol Biol 215: 403-410.

Aluwihare LI, Repeta DJ. (1999). A comparison of the chemical characteristics of oceanic DOM and extracellular DOM produced by marine algae. Mar Ecol Prog Ser 186: 105-117.

Ammerman JW, Fuhrman JA, Hagström Å, Azam F. (1984). Bacterioplankton growth in seawater: I. Growth kinetics and cellular characteristics in seawater cultures. Marine ecology progress series. Oldendorf 18: $31-39$.

Amon RMW, Fitznar H-P, Benner R. (2001). Linkages among the bioreactivity, chemical composition, and diagenetic state of marine dissolved organic matter. Limnol Oceanogr 46: 287-297.

Anastasakis K, Ross AB, Jones JM. (2011). Pyrolysis behaviour of the main carbohydrates of brown macro-algae. Fuel 90: 598-607.

Arias-Gonzalez J, Delesalle B, Salvat B, Galzin R. (1997). Trophic functioning of the Tiahura reef sector, Moorea Island, French Polynesia. Coral Reef 16: 231-246.

Arnosti C. (2011). Microbial Extracellular Enzymes and the Marine Carbon Cycle. Ann Rev Mar Sci 3: 401-425.

Arnosti C, Steen AD, Ziervogel K, Ghobrial S, Jeffrey WH. (2011). Latitudinal gradients in degradation of marine dissolved organic carbon. PLOS ONE 6: e28900.

Badger JH, Eisen JA, Ward NL. (2005). Genomic analysis of Hyphomonas neptunium contradicts $16 \mathrm{~s}$ rrna gene-based phylogenetic analysis: implications for the taxonomy of the orders 'Rhodobacterales' and Caulobacterales. Int J Syst Evol Microbiol 55: 1021-1026.

Bally M, Garrabou J. (2007). Thermodependent bacterial pathogens and mass mortalities in temperate benthic communities: a new case of emerging disease linked to climate change. Global Change Biol 13: 2078-2088.

Barott K, Smith J, Dinsdale E, Hatay M, Sandin S, Rohwer F. (2009). Hyperspectral and physiological analyses of coral-algal interactions. Plos One 4: e8043.

Barott KL, Rodriguez-Brito B, Janouškovec J, Marhaver KL, Smith JE, Keeling P et al. (2011). Microbial diversity associated with four functional groups of benthic reef algae and the reef-building coral Montastraea annularis. Environ Microbiol 13: 1192-1204.

Barott KL, Rodriguez-Mueller B, Youle M, Marhaver KL, Vermeij MJA, Smith JE et al. (2012). Microbial to reef scale interactions between the reef-building coral Montastraea annularis and benthic algae. Proc Roy Soc B-Biol Sci 279: 1655-1664.

Ben-Haim Y, Thompson F, Thompson C, Cnockaert M, Hoste B, Swings J et al. (2003). Vibrio coralliilyticus sp nov., a temperature-dependent pathogen of the coral Pocillopora damicornis. Int J Syst Evol Microbiol 53: 309-315.

Benner R. (2002). Chemical composition and reactivity. In Hansell DA, Carlson CA (eds), Biogeochemistry of Marine Dissolved Organic Matter, Academic Press: San Diego, CA, USA, pp 59-90.

Birrell C, Mccook L, Willis B, Diaz-Pulido G. (2008). Effects of benthic algae on the replenishment of corals and the implications for the resilience of coral reefs. In Gibson R, Atkinson R, Gordon J (eds), Oceanography and Marine Biology. CRC Press: Boca Raton, FL, USA, pp 25-63.

Brown A. (2012). The influence of water flow on mechanisms underlying coral-algal interactions. California State University: Northridge.

Carlson C, Ducklow H. (1996). Growth of bacterioplankton and consumption of dissolved organic carbon in the Sargasso Sea. Aquat Microb Ecol 10: 69-85.

Carlson C, Hansell D, Nelson N, Siegel D, Smethie W, Khatiwala S et al. (2010). Dissolved organic carbon export and subsequent remineralization in the mesopelagic and bathypelagic realms of the North Atlantic basin. Deep Sea Res Part II 57: 1433-1445.

Carlson CA. (2002). Production and removal processes. In Hansell DA, Carlson CA (eds), Biogeochemistry of Marine Dissolved Organic Matter. Academic Press: San Diego, CA, USA, pp 91-151.

Carlson CA, Giovannoni SJ, Hansell DA, Goldberg SJ, Parsons R, Vergin K. (2004). Interactions among dissolved organic carbon, microbial processes, and community structure in the mesopelagic zone of the northwestern Sargasso Sea. Limnol Oceanogr 49: 1073-1083.

Carlton R, Richardson L. (1995). Oxygen and sulfide dynamics in a horizontally migrating cyanobacterial mat - black band disease of corals. FEMS Microbiol Ecol 18: 155-162.

Chadwick NE, Morrow KM. (2011). Competition Among sessile organisms on coral reefs. In Dubinsky Z, Stambler N (eds) Coral Reefs: An Ecosystem in Transition. Springer: Netherlands, pp 347-371.

Chattopadhyay N, Ghosh T, Sinha S, Chattopadhyay K, Karmakar P, Ray B. (2010). Polysaccharides from Turbinaria conoides: Structural features and antioxidant capacity. Food Chem 118: 823-829.

Chen L. (2004). VFDB: a reference database for bacterial virulence factors. Nucleic Acids Res 33: D325-D328.

Coenye T, Vandamme P. (2003). Diversity and significance of Burkholderia species occupying diverse ecological niches. Environ Microbiol 5: 719-729.

Coffroth MA. (1990). Mucous sheet formation on poritid corals: An evaluation of coral mucus as a nutrient source on reefs. Mar Biol 105: 39-49.

Colwell R, Huq A. (2001). Marine ecosystems and cholera. Hydrobiologia 460: 141-145.

Cooney R, Pantos O, Le Tissier M, Barer M, O’Donnell A, Bythell J. (2002). Characterization of the bacterial 
consortium associated with black band disease in coral using molecular microbiological techniques. Environ Microbiol 4: 401-413.

Costa-Ramos C, Rowley AF. (2004). Effect of extracellular products of Pseudoalteromonas atlantica on the edible crab Cancer pagurus. Appl Environ Microbiol 70: 729-735.

Cottrell MT, Kirchman DL. (2000). Natural assemblages of marine proteobacteria and members of the CytophagaFlavobacter cluster consuming low-and high-molecular-weight dissolved organic matter. Appl Environ Microbiol 66: 1692.

Cowie GL, Hedges JI. (1994). Biochemical indicators of diagenetic alteration in natural organic matter mixtures. Nature 369: 304-307.

Diaz-Pulido G, McCook LJ. (2002). The fate of bleached corals: patterns and dynamics of algal recruitment. Mar Ecol Prog Ser 232: 115-128.

Dinsdale EA, Rohwer F. (2011). Fish or germs? microbial dynamics associated with changing trophic structures on coral reefs. In Dubinsky Z, Stambler N (eds) Coral Reefs: An Ecosystem in Transition. Springer: Netherlands, pp 231-240.

Done TJ. (1992). Phase shifts in coral reef communities and their ecological significance. Hydrobiologia 247: 121-132.

Ducklow H. (1990). The biomass, production and fate of bacteria in coral reefs. Ecosystems of the world 25: 265-289.

Elifantz H, Malmstrom RR, Cottrell MT, Kirchman DL. (2005). Assimilation of polysaccharides and glucose by major bacterial groups in the Delaware Estuary. Appl Environ Microbiol 71: 7799-7805.

Forsman Z, Barshis D, Hunter C, Toonen R. (2009). Shapeshifting corals: molecular markers show morphology is evolutionarily plastic in Porites. BMC Evol Biol 9: 45.

Gennari M, Ghidini V, Lleo Mm. (2012). Virulence genes and pathogenicity islands in environmental Vibrio strains non-pathogenic to humans. FEMS Microbiol Ecol 82: 563-573.

Goldberg SJ, Carlson CA, Bock B, Nelson NB, Siegel DA. (2010). Meridional variability in dissolved organic matter stocks and diagenetic state within the euphotic and mesopelagic zone of the North Atlantic subtropical gyre. Mar Chem 119: 9-21.

Goldberg SJ, Carlson CA, Brzezinski M, Nelson NB, Siegel DA. (2011). Systematic removal of neutral sugars within dissolved organic matter across ocean basins. Geophys Res Lett 38: 7. PP.

Goldberg SJ, Carlson CA, Hansell DA, Nelson NB, Siegel DA. (2009). Temporal dynamics of dissolved combined neutral sugars and the quality of dissolved organic matter in the Northwestern Sargasso Sea. Deep Sea Res Part I 56: 672-685.

Grigg R, Polovina J, Atkinson M. (1984). Model of a coral reef ecosystem. Coral Reef 3: 23-27.

Haapkylae J, Unsworth RKF, Flavell M, Bourne DG, Schaffelke B, Willis BL. (2011). Seasonal rainfall and runoff promote coral disease on an inshore reef. PLOS One 6: e16893.

Haas A, el-Zibdah M, Wild C. (2009). Seasonal monitoring of coral-algae interactions in fringing reefs of the Gulf of Aqaba, Northern Red Sea. Coral Reef 29: 93-103.

Haas AF, Nelson CE, Wegley Kelly L, Carlson CA, Rohwer F, Leichter JJ et al. (2011). Effects of coral reef benthic primary producers on dissolved organic carbon and microbial activity. PLoS ONE 6: e27973.

Haas AF, Wild C. (2010). Composition analysis of organic matter released by cosmopolitan coral reef-associated green algae. Aquat Biol 10: 131-138.

Hagström A, Ammerman JW, Henrichs S, Azam F. (1984). Bacterioplankton growth in seawater: II. Organic matter utilization during steady-state growth in seawater cultures. Marine ecology progress series. Oldendorf 18: 41-48.

Hansell DA, Carlson CA. (2002). Biogeochemistry of marine dissolved organic matter. Academic Press.

Harvell C, Kim K, Burkholder J, Colwell R, Epstein P, Grimes D et al. (1999). Review: marine ecologyemerging marine diseases-climate links and anthropogenic factors. Science 285: 1505-1510.

Hauri C, Fabricius KE, Schaffelke B, Humphrey C. (2010). Chemical and physical environmental conditions underneath mat- and canopy-forming macroalgae, and their effects on understorey corals. Humphries S (ed) PLoS ONE 5: e12685.

Hughes TP. (1994). Catastrophes, phase shifts, and largescale degradation of a caribbean coral reef. Science 265: 1547-1551.

Hughes TP, Rodrigues MJ, Bellwood DR, Ceccarelli D, Hoegh-Guldberg O, McCook L et al. (2007). Phase shifts, herbivory, and the resilience of coral reefs to climate change. Curr Biol 17: 360-365.

Jani AJ, Cotter PA. (2010). Type VI secretion: not just for pathogenesis anymore. Cell Host Microbe 8: 2-6.

Jensen A. (1993). Present and future needs for algae and algal products. Hydrobiologia 260-261: 15-23.

Jompa J, McCook LJ. (2003). Coral-algal competition: macroalgae with different properties have different effects on corals. Mar Ecol Prog Ser 258: 87-95.

Jordan EM, Thompson FL, Zhang X-H, Li Y, Vancanneyt M, Kroppenstedt RM et al. (2007). Sneathiella Chinensis Gen. Nov., Sp. Nov., a novel marine alphaproteobacterium isolated from coastal sediment in Qingdao, China. Int J Syst Evol Microbiol 57: 114-121.

Kaiser K, Benner R. (2009). Biochemical composition and size distribution of organic matter at the Pacific and Atlantic time-series stations. Mar Chem 113: 63-77.

Karl DM, Hebel DV, Bjorkman K, Letelier RM. (1998). The role of dissolved organic matter release in the productivity of the oligotrophic North Pacific Ocean. Limnol Oceanogr 43: 1270-1286.

Kelly LW, Barott KL, Dinsdale E, Friedlander AM, Nosrat B, Obura D et al. (2012). Black reefs: iron-induced phase shifts on coral reefs. ISME J 6: 638-649.

Kirchman DL, Meon B, Ducklow HW, Carlson CA, Hansell DA, Steward GF. (2001). Glucose fluxes and concentrations of dissolved combined neutral sugars (polysaccharides) in the Ross Sea and Polar Front Zone, Antarctica. Deep Sea Res Part II 48: 4179-4197.

Koblížek M, Béjà O, Bidigare RR, Christensen S, BenitezNelson B, Vetriani C et al. (2003). Isolation and characterization of Erythrobacter sp. strains from the upper ocean. Arch Microbiol 180: 327-338.

Kushmaro A, Banin E, Loya Y, Stackebrandt E, Rosenberg E. (2001). Vibrio shiloi sp nov., the causative agent of bleaching of the coral Oculina patagonica. Int $J$ Syst Evol Microbiol 51: 1383-1388.

Ledlie MH, Graham NAJ, Bythell JC, Wilson SK, Jennings S, Polunin NVC et al. (2007). Phase shifts and the role of herbivory in the resilience of coral reefs. Coral Reef 26: 641-653. 
Lee S, Fuhrman JA. (1987). Relationships between biovolume and biomass of naturally derived marine bacterioplankton. Appl Environ Microbiol 53: 1298-1303.

Lirman D. (2001). Competition between macroalgae and corals: effects of herbivore exclusion and increased algal biomass on coral survivorship and growth. Coral Reef 19: 392-399.

Littler MM, Littler DS. (1997). Epizoic red alga allelopathic (?) to a Caribbean coral. Coral Reef 16: 168.

Marhaver KL, Vermeij MJA, Rohwer F, Sandin SA. (2012). Janzen-Connell effects in a broadcast-spawning Caribbean coral: Distance-dependent survival of larvae and settlers. Ecology doi:10.1890/12-0985.1.

McCliment EA, Nelson CE, Carlson CA, Alldredge AL, Witting J, Amaral-Zettler LA. (2011). An all-taxon microbial inventory of the Moorea coral reef ecosystem. ISME J 6: 309-319.

McCook L, Jompa J, Diaz-Pulido G. (2001). Competition between corals and algae on coral reefs: a review of evidence and mechanisms. Coral Reef 19: 400-417.

McCook LJ. (1999). Macroalgae, nutrients and phase shifts on coral reefs: scientific issues and management consequences for the Great Barrier Reef. Coral Reef 18: 357-367.

Meikle P, Richards GN, Yellowlees D. (1988). Structural investigations on the mucus from six species of coral. Mar Biol 99: 187-193.

Nelson CE, Alldredge AL, McCliment EA, Amaral-Zettler LA, Carlson CA. (2011). Depleted dissolved organic carbon and distinct bacterial communities in the water column of a rapid-flushing coral reef ecosystem. ISME J 5: 1374-1387.

Nelson CE, Carlson CA. (2011). Differential response of high-elevation planktonic bacterial community structure and metabolism to experimental nutrient enrichment. Gilbert J (ed.) PLOS ONE 6: e18320.

Nelson CE, Carlson CA. (2012). Tracking differential incorporation of dissolved organic carbon types among diverse lineages of Sargasso Sea bacterioplankton. Environ Microbiol 14: 1500-1516.

Niggl W, Haas AF, Wild C. (2010). Benthic community composition affects $\mathrm{O} 2$ availability and variability in a Northern Red Sea fringing reef. Hydrobiologia 644: 401-405.

Nyström M. (2006). Redundancy and response diversity of functional groups: implications for the resilience of coral reefs. Ambio 35: 30-35.

Overbeek R. (2005). The subsystems approach to genome annotation and its use in the project to annotate 1000 genomes. Nucleic Acids Res 33: 5691-5702.

Pakulski JD, Benner R. (1994). Abundance and distribution of carbohydrates in the ocean. Limnol Oceanogr 39: 930-940.

Pandolfi JM, Bradbury RH, Sala E, Hughes TP, Bjorndal KA, Cooke RG et al. (2003). Global trajectories of the long-term decline of coral reef ecosystems. Science 301: 955-958.

Park S, Lee M-H, Lee J-S, Oh T-K, Yoon J-H. (2012). Thalassobius Maritimus sp. Nov., isolated from seawater. Int J Syst Evol Microbiol 62: 8-12.

Percival E. (1979). The polysaccharides of green, red and brown seaweeds: their basic structure, biosynthesis and function. Br Phycol J 14: 103-117.

Rasher DB, Hay ME. (2010). Chemically rich seaweeds poison corals when not controlled by herbivores. Proc Natl Acad Sci USA 107: 9683-9688.
Rich JH, Ducklow HW, Kirchman DL. (1996). Concentrations and uptake of neutral monosaccharides along $140^{\circ} \mathrm{W}$ in the equatorial Pacific: contribution of glucose to heterotrophic bacterial activity and the DOM flux. Limnol Oceanogr 41: 595-604.

River GF, Edmunds PJ. (2001). Mechanisms of interaction between macroalgae and scleractinians on a coral reef in Jamaica. J Exp Mar Bio Ecol 261: 159-172.

Rosenberg E, Koren O, Reshef L, Efrony R, ZilberRosenberg I. (2007). The role of microorganisms in coral health, disease and evolution. Nat Rev Microbiol 5: 355-362.

Rosenberg E, Kushmaro A, Kramarsky-Winter E, Banin E, Yossi L. (2009). The role of microorganisms in coral bleaching. ISME J 3: 139-146.

Skoog A, Benner R. (1997). Aldoses in various size fractions of marine organic matter: Implications for carbon cycling. Limnol Oceanogr 42: 1803-1813.

Smith JE, Hunter CL, Smith CM. (2010). The effects of topdown versus bottom-up control on benthic coral reef community structure. Oecologia 163: 497-507.

Smith JE, Shaw M, Edwards RA, Obura D, Pantos O, Sala E et al. (2006). Indirect effects of algae on coral: algaemediated, microbe-induced coral mortality. Ecol Lett 9: $835-845$.

Smith WO, Carlson CA, Ducklow HW, Hansell DA. (1998). Growth dynamics of phaeocystis antarctica-dominated plankton assemblages from the Ross Sea. Mar Ecol Prog Ser 168: 229-244.

Sorokin Y. (1990). Aspects of trophic relations, productivity and energy balance in coral-reef ecosystems. Ecosystems of the world 25: 401-418.

Stahl DA, Key R, Flesher B, Smit J. (1992). The phylogeny of marine and freshwater caulobacters reflects their habitat. J Bacteriol 174: 2193-2198.

Storey JD, Tibshirani R. (2003). Statistical significance for genomewide studies. Proc Nat Acad Sci Usa 100: 9440.

Urios L, Intertaglia L, Lesongeur F, Lebaron P. (2008). Haliea salexigens gen. nov., sp. nov., a member of the gammaproteobacteria from the mediterranean sea. Int $J$ Syst Evol Microbiol 58: 1233-1237.

Vermeij MJA, Smith JE, Smith CM, Thurber RV, Sandin SA. (2009). Survival and settlement success of coral planulae: independent and synergistic effects of macroalgae and microbes. Oecologia 159: 325-336.

Wada S, Aoki MN, Tsuchiya Y, Sato T, Shinagawa H, Hama T. (2007). Quantitative and qualitative analyses of dissolved organic matter released from Ecklonia cava Kjellman, in Oura Bay, Shimoda, Izu Peninsula, Japan. J Exp Mar Bio Ecol 349: 344-358.

Wegley L, Edwards R, Rodriguez Brito B, Liu H, Rohwer F. (2007). Metagenomic analysis of the microbial community associated with the coral Porites astreoides. Environ Microbiol 9: 2707-2719.

Weiner RM, Melick M, O’Neill K, Quintero E. (2000). Hyphomonas adhaerens Sp. Nov., Hyphomonas johnsonii Sp. Nov. and Hyphomonas rosenbergii Sp. Nov., marine budding and prosthecate bacteria. Int $J$ Syst Evol Microbiol 50: 459-469.

Wetzel RG, Likens GE. (2000). Limnological analyses. Springer Verlag.

Wild C, Naumann M, Niggl W, Haas A. (2010). Carbohydrate composition of mucus released by scleractinian warmand cold-water reef corals. Aquat Biol 10: 41-45.

Supplementary Information accompanies the paper on The ISME Journal website (http://www.nature.com/ismej) 